\title{
THE ETIOLOGY
}

of

TYPHUS EXANTHEMATICUS
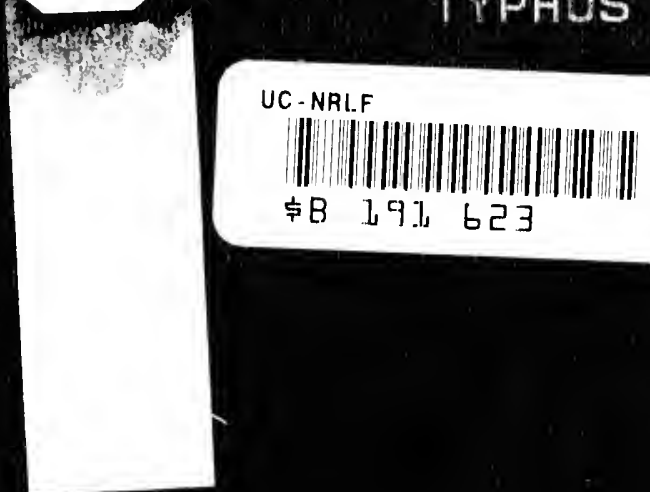

PLOTZ - OLITSKY - BAEHR 
To Dr lacquer Poet, with our affereciation of you hind interest,

Kerry Tach.

Hang Alts

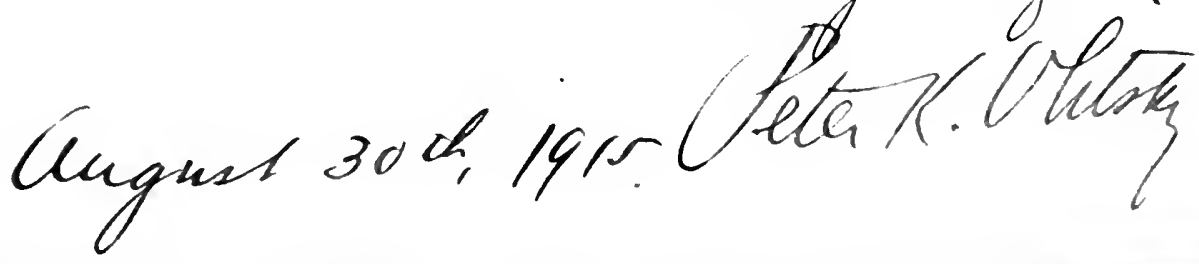




\title{
THE ETIOLOGY \\ OF \\ TYPHUS EXANTHEMATICUS
}

\author{
HARRY PLOTZ \\ PETER K. OLITSKY \\ AND \\ GEORGE BAEHR
}




\section{RC 199 \\ P6 \\ BIOLOEY}

-FROM-THE.

-SCIENTIFIC - LIBRARY O OF • - JACQUES - LOEB.

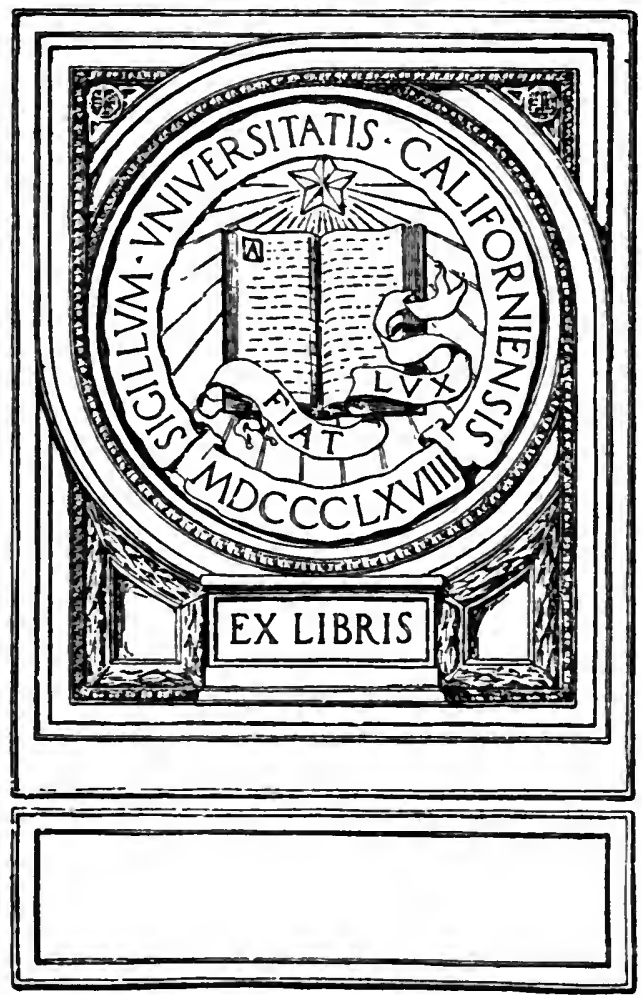




\section{DR. EMANUEL LIBMAN}

this work is dedicated by the authors as a token of their esteem and affection 


\section{Digitized by the Internet Archive in 2007 with funding from Microsoft Corporation}




\section{THE ETIOLOGY OF TYPHUS EXANTHEMATICUS}

\section{(WITH PLATE 1)}

harry Plotz, Peter K. Olitsky, and George Baehr

(From the Pathological Laboratory, Mount Sinai Hospital, New York)

\section{BACTERIOLOGIC STUDIES}

HARRY PLOTZ

In a preliminary communication ${ }^{105}$ in 1914, I described an organism which I considered to be the etiologic agent in typhus exanthematicus. The organism, a bacillus, was recovered from the blood of five cases of European epidemic typhus fever and of six cases of the mild endemic form of the disease, known in the United States as Brill's disease and designated in these papers endemic typhus fever. Since that time, I have had the opportunity of studying a much larger series of cases with the same cultural methods, and the results, together with the serologic and experimental studies, have confirmed the opinion then expressed. At the present time, we shall give only those data which bear upon the question of etiology, leaving other phases of the work for future reports.

A variety of organisms, bacilli, cocci, spirilla, and protozoa, have been reported as being recovered from cases of epidemic typhus fever. Some were only asserted to have been seen in stained specimens of the blood, others were reported to have been cultivated from the blood with more or less regularity. I shall not describe these findings because none of them corresponds to the organism which I have isolated. In particular, as will be seen later, I was unable to confirm the work of Rabinowitsch,109, 110, 111, 112, 113, 114, 115 whose work seemed more plausible than that of his predecessors.

The endemic form of typhus fever is characterized by its comparatively mild course and very low mortality. We owe its differ-

For the financial support of these investigations, the authors are indebted to two contributors who desire to remain anonymous. 
entiation from other fevers seen in New York, especially short term typhoids, to the clinical insight of Dr. Nathan E. Brill. ${ }^{25}$ Some years after the attention of the profession had been called to this condition, its similarity to typhus fever was noted. A Committee appointed by the Section of Medicine of the New York Academy of Medicine ${ }^{116}$ stated in their report to the Academy on December 20, 1910, that they were convinced that the cases described by Brill were not instances of typhoid or paratyphoid fever. They were unwilling to decide whether these cases represented an atypical form of some already recognized disease, or were instances of a disease previously unrecognized. Shortly after this, Louria ${ }^{76}$ and G. A. Friedman ${ }^{45}$ published papers emphasizing the resemblance of these cases to cases of mild typhus fever which they had seen in Europe.

The striking cross immunity experiments of Anderson and Goldberger $^{6}$ demonstrated that the disease described by Brill was most likely a mild form of typhus fever. They showed that the blood from cases of this disease was infective for monkeys, these animals developing, after a varying incubation period, a febrile reaction which ended by crisis, or rapid lysis, their blood being infections for other monkeys and guinea-pigs. They also proved that animals which had reacted to the inoculation of such blood were immune to inoculation with the blood from cases of Mexican typhus fever. Likewise, animals that had reacted to inoculation of blood from cases of Mexican typhus fever were refractory to the inoculation of blood from cases of the type described by Brill.

I began my studies with the endemic form of the disease, using the viewpoints that had been established regarding typhus fever. It was very fortunate that after I had isolated an organism in a number of cases, the unusual opportunity was afforded me of investigating cases of classical typhus fever, and of definitely establishing the identity of the two conditions.

In the search for the etiology of typhus fever, one of the most important aids was the fact that the virus of typhus fever had been demonstrated as existing in the circulating blood during the febrile period of the disease. This was first proved by the human experiment of Moczutkowski, ${ }^{81}$ who inoculated himself with typhus blood and, after an incubation period of eighteen days, developed the 
typical symptoms of the disease. This result was confirmed by the human experiments of Otero, ${ }^{102}$ and of Yersin and Vassal, ${ }^{135}$ and the animal experiments of all subsequent workers, Nicolle, ${ }^{88}$ Anderson and Goldberger, ${ }^{16}$ Ricketts and Wilder, ${ }^{117}$ Gavino and Girard, ${ }^{51}$ and McCampbell. ${ }^{79}$

The possibility that the virus might be ultramicroscopic-a possibility improperly stated as a fact in some text books-was suggested by a single dubious experiment of Nicolle, ${ }^{98}$ which neither he himself ${ }^{92}$ nor Ricketts and Wilder, ${ }^{131}$ Anderson and Goldberger, ${ }^{16}$ nor Gavino and Girard ${ }^{51}$ was subsequently able to confirm. In this experiment, a monkey which had been inoculated with Berkefeld filtered serum (from clotted typhus blood) presented an elevation of temperature of $0.5 \mathrm{C}$. between the sixteenth and eighteenth days after inoculation. This animal when subsequently inoculated with typhus blood did not react. The criticism of Anderson and Goldberger $^{16}$ that the frequent occurrence of a natural immunity in monkeys must be considered as a possible explanation of this refractoriness on the part of the particular monkey to re-inoculation of the virus, completely upsets the value of this single experiment. On the contrary, the subsequent work of Nicolle, ${ }^{92}$ Ricketts and Wilder, ${ }^{113}$ Gavino and Girard, ${ }^{51}$ and especially of Anderson and Goldberger, ${ }^{16}$ all points to the fact that the virus of typhus fever is non-filtrable. We may assume then that the virus is of microscopic size.

The fact that the virus of typhus fever is not filtrable was probably the stimulus which induced Ricketts and Wilder ${ }^{119}$ to examine the blood microscopically in a number of cases. These investigators described a bacillus which they saw in blood smears stained with the Giemsa method. This bacillus apparently does bear a certain morphologic resemblance to the organism which I have cultivated, but one can not prove the identity of these two organisms by morphologic criteria alone. As the reaction of this organism to Gram's stain is not mentioned, we are thrown further in doubt because a number of morphologically similar organisms, gram-negative and grampositive, have been described in typhus fever. There is no evidence, then, that the bacillus seen by Ricketts and Wilder is the same as that which forms the basis of this report. Fried and Sophian, ${ }^{44}$ altho they made a prolonged microscopic search, could find no organisms 
in smears of blood made from five cases of endemic typhus fever. It is of interest that these observers described in the blood of a variety of cases of bacteriemia the frequent occurrence of bodies which morphologically correspond to bacilli and which are decolorized by Gram's stain.

It was surmised that, since typhus fever had been proved to be an insect-borne disease, a protozoan origin would needs be found; but Ricketts and Wilder, ${ }^{110}$ in refutation, called attention to the fact that the flea carries the bacillus of plague, as does the tick the spirillum of African tick fever. The same authors also pointed out that typhus fever is an acute, self-limited disease and that one attack,confers immunity - features characteristic of many bacterial diseases but extremely unusual in protozoan infections.

The evidence here adduced indicates therefore, first, that the virus of typhus fever is present in the blood during the febrile period of the disease; second, that it is non-filtrable, and therefore most likely of microscopic size; and third, that it is probably of bacterial, rather than of protozoan nature. These facts actuated the majority of recent workers, including myself, to attempt to cultivate the virus irom the blood of cases of typhus fever. For this purpose aerobic methods of culture had generally been used, notably by Anderson and Goldberger ${ }^{16}$ and Ricketts and Wilder, ${ }^{119}$ with negative results.

In the Laboratory of the Mount Sinai Hospital, the blood of over three hundred cases of endemic typhus fever has been studied by aerobic methods, with uniformly negative results. The media used were plates of agar and glucose agar (often with ascitic fluid added) and flasks of broth and 2 percent glucose broth (both with and without ascitic fluid), the flasks containing 100 c.c. and occasionally 250 c.c. of fluid.

In the search for the cause of typhus fever, I not only repeated the aerobic methods of other workers, including Rabinowitsch, ${ }^{109,}{ }^{115}$ Pretjetschensky, ${ }^{106,}{ }^{10 i}$ Mueller, ${ }^{84,}{ }^{85}$ and Fuerth, ${ }^{4 i,}+8,{ }^{49}$ with negative results, but also used anaerobic methods of cultivation-a procedure which curiously enough had not been previously employed.

$\mathrm{Up}_{\mathrm{p}}$ to the present time, eleven cases of European epidemic typhus fever and forty cases of the local endemic form of the disease have been studied. Most of the epidemic cases occurred in individuals returning to America after the Balkan wars. The diagnosis was 
made by Dr. Joseph J. O'Connell, Health Officer of the Port of New York, to whom I wish to express my thanks for his valuable cooperation and numerous courtesies, and also to Dr. S. S. Goldwater, Commissioner of Health of the City of New York, who kindly drew the attention of Dr. O'Connell to these investigations. Of the forty endemic cases, thirty-six were patients in the wards of the Mount Sinai Hospital, for the opportunity of studying which I wish to thank Dr. Meyer, Dr. Brill, Dr. Manges, and Dr. Libman, the attending physicians of the Hospital. For the other four cases, I am indebted to Dr. Arthur Stern, of the Alexian Brothers Hospital, Elizabeth, New Jersey, Dr. Thomas J. Dunn, of the Fordham Hospital, and Dr. E. P. Bernstein, who cultured one case at the Lebanon Hospital and turned the organism over to me for further study.

We wish to thank Dr. F. S. Mandlebaum, Director of the Laboratory of Mount Sinai Hospital, for many courtesies and for placing all the facilities of the Department at our disposal.

This work, as well as the investigations which form the basis of the subsequent papers, was carried out under the direction and with the helpful assistance of Dr. E. Libman. It was the energy and stimulus which he supplied to the work which helped us carry it to a successful conclusion.

\section{Methods of Culture}

Withdrazul of the Blood.-The antecubital space is thoroughly washed for about two minutes with tincture of green soap and warn 1 water, followed by alcohol, ether, and a 1:1000 solution of bichlorid of mercury. A tourniquet is then applied to the arm above the elbow with sufficient pressure to produce venous stasis. A distended vein in the antecubital space is then punctured and 15 c.c. of blood withdrawn. This blood is immediately distributed among the various media.

Aerobic Methods.-The aerobic method of blood culture followed is the same as that which has been employed at the Mount Sinai Hospital as a routine procedure in over five thousand febrile cases. Two plates of agar and two of glucose agar are poured, the remainder of the blood being distributed in one or more flasks ( 100 c.c.) of broth and of 2 percent glucose broth. The agar, in concentration of 2-3 percent, is prepared with Liebig's meat extract, and is of 0.9-1:1 percent acidity. Before use, the tubes of agar are melted by boiling in water and are then cooled to $40 \mathrm{C}$. before the blood is added.

To each of the four tubes of plain and glucose agar, 2 c.c. of blood are added and mixed by pouring the contents back and forth into a sterile test tube. The resultant mixture is then emptied into four Petri dishes and allowed to harden. To each of the two flasks of broth, about 2 c.c. of blood are added and the vessels gently agitated to secure thorough mixing. 
Because of the report by Rabinowitsch ${ }^{100115}$ that he had obtained positive blood cultures in cases of typhus fever by the use of an aerobic method, his medium was tested. It consists of equal quantities of broth and ascitic fluid with 4 percent of glycerin added. To a flask containing 100 c.c. of this medium, 5 c.c. of blood are added. This method was used in five cases of epidemic, and seven of endemic typhus fever. Into each flask, 3-10 c.c. of blood were inoculated. The results were entirely negative, altho of these cases, four of the epidemic and two of the endemic gave positive results with the anaerobic method of cultivation.

Anaerobic Methods.-In the early part of this study a number of anaerobic methods were employed without success. The first successful results were obtained by the use of the ascitic fluid, kidney tissue, liquid petrolatum medium as advocated for the cultivation of spirochæatae by Dr. Noguchi, to whom I am indebted for a demonstration of his methods. By the use of this method, the organism was obtained in two cases of endemic, and one of epidemic typhus fever. The method of Liborius-Veillon ${ }^{72}$ proved to be more satisfactorymodified, in that serum glucose agar, originally suggested by Libman as an optimal medium, was used instead of glucose agar.

Tubes measuring $15 \mathrm{~cm}$. in length and $2 \mathrm{~cm}$. in diameter are employed, each containing about 20 c.c. of 2 percent glucose agar. The agar is of a 2 percent concentration, and is made up with Liebig's meat extract. The acidity of the medium varies from 0.9 to 1.1 percent.

Eight such tubes are now used for each blood culture. The medium is first melted by boiling the tubes in water, and then cooled to $40 \mathrm{C}$. before use. Into each tube, about 2 c.c. of blood are injected directly from the syringe, and to this mixture about 4 c.c. of ascitic fluid are added. The contents are then thoroughly mixed by pouring back and forth into a sterile test tube. It is essential that this procedure be carried out very gently to avoid introducing air bubbles. The tubes are then allowed to cool at room temperature, or are more rapidly cooled by immersion in a vessel containing ice water. This hastens hardening and limits the absorption of oxygen. When the medium is hardened, a laye of plain agar 2 c.c. deep is added to each tube. The tubes are then incubated at $37.5 \mathrm{C}$. and observed daily by transmitted sun light, or electric light, colonies of bacteria appearing as opaque bodies.

Serum Employed.-The success of a culture depends in great part upon the proper selection of the serum. Hydrocele fluid was used with success in the earlier cultures, but as our supply was soon exhausted, ascitic fluid was substituted. It was found that only such sera should be employed which are bilefree and have a specific gravity of 1015 or over.

The sterility of the fluid must be ascertained by aerobic and anaerobic methods. The aerobic method used consists in adding 5 c.c. of ascitic fluid to each of three tubes of a 2 percent glucose agar, each tube containing about 20 c.c. of agar. This serum agar mixture is then poured into Petri plates and incubated at $37.5 \mathrm{C}$. If growth is detected during a seven-day period of observation, the fluid is discarded.

The anaerobic method consists in adding 5 c.c. of serum to each of three tubes of 2 percent glucose agar, each tube containing about 20 c.c. of the medium. To each of another set of three tubes are added 2 c.c. of ox blood, sterilized by the formalin method described by Bernstein and Epstein. ${ }^{21}$ This 
is done to rule out the possible presence of hemoglobinophilic organisms. These six tubes are observed for twenty days, this length of time being essential because of the occasional late development of saprophytic organisms.

It was considered important to study the bacteriology of ascitic fluids. Fortyfour different specimens (for which I wish to thank Dr. Noguchi, Dr. Libman, and Dr. Bernstein) were examined with the method described. The saprophytic bacilli occurring in rabbit kidney tissue were also similarly studied. Altho a number of aerobic and anaerobic microörganisms were encountered, none having the cultural characteristics of the organism later to be described was isolated. Furthermore, antigen made from these organisms did not react in a specific manner with typhus immune serum - as shown in the paper by Dr. Olitsky.

Development of Colonies of the Organism Obtained: Subinoculations.Colonies of the organism appear in the tubes in from three to sixteen days. They may appear at different times in the same tube. It is important to observe the tubes for a long time, twenty-one days being the arbitrary limit in my work. The tubes are opened by making a circular scratch with a file just above the site of the colony to be removed. On breaking the tube across, the agar is dropped into a sterile Petri dish. It is not necessary first to immerse the tube in carbolic acid, or bichlorid of mercury. A firm platinum loop is used to remove the agar overlying the colony. A portion of the colony is then removed and inoculated on slants of 0.5 percent glucose serum agar (one-fourth volume of serum). The inoculated tubes are placed in Buchner tubes, $20 \mathrm{~cm}$. in length and $2.5 \mathrm{~cm}$. in diameter, containing about $25 \mathrm{c} . \mathrm{c}$. of a 40 percent solution of potassium hydrate and $3 \mathrm{gm}$. of pyrogallic acid. The Buchner tubes are firmly sealed with a tightly fitting rubber stopper.

After the removal of the large colonies with the loop, the remaining agar is sliced with a sterile scalpel so that any small colonies may be detected. This method of removing colonies necessitates the destruction of the medium, so that the subsequent development of colonies, which have not yet matured, is interfered with. The method of removing colonies with a capillary pipette as soon as they appear, is not as valuable because the technic is a more difficult one to acquire. Furthermore, the anaerobic value of the medium is destroyed by the introduction of the pipette.

\section{DESCRIPTION OF THE ORGANISM}

Colonies.-Colonies usually appear in the lower two or three centimeters of the tube, occasionally higher, but never within three centimeters from the top of the medium. The colony first appears as a small, opaque spot. As it grows larger, a brownish area of precipitation* develops in the medium about it. By direct sunlight or incandescent electric light (frosted bulb), the colony itself appears, round and opaque, varying from 1 to $6 \mathrm{~mm}$. in diameter (including the area of precipitation), the size of the colony depending

* This phenomenon was first described by Dr. Libman ${ }^{73} 74$ when he advised the use of media containing carbohydrates and sera (non-cuagulated) for the growth of poorly growing organisms. The phenomenon occurs if acid is produced from a given carbohydrate and if sufficient growth is present to bring the acidity up to the point necessary to cause precipitation of the protein. In fluid meaia, a distinct, heavy precipitate is found. In solid media, there occurs a diffuse, marked whitening of the media. When blood is also present, the area of precipitation is usually of a brownisl color. 
on its stage of development. On cross section, it is $\mathrm{Y}$-shaped, brownish in appearance, and soft in consistency. The arms of the $Y$ are fusiform.

Morphology.-The organism is a small, pleomorphic, gram-positive bacillus, not motile, not encapsulated, and not acid fast. Its length varies from 0.9 to 1.93 microns, its breadth being from onefifth to three-fifths its length. Most of the organisms are straight; occasional ones are slightly curved. Coccoid forms also occur. The ends are rounded or slightly pointed. In smears from solid media, the organisms lie end to end, side by side, or at angles to one another, there being no definite arrangement. Degeneration and involution forms appear early, so that after repeated transplants the organism may assume a different morphologic appearance from the bacilli in the original culture.

The organism produces no spores. Polar bodies are occasionally demonstrable with the pyoktanin, acetic acid, Bismarck brown stain (Ljubinski ${ }^{i 5}$ ). When present, they usually appear at one end of the bacillus, but may appear at both ends.

Cultural Characteristics.-The methods used in this study for determining the cultural characteristics of the organism are suggested as a basis for future studies of all anaerobic organisms. At present anaerobic bacteria are cultivated on such varying kinds of media that an accurate classification is not possible. This classification is based mainly on the work of Dr. Noguchi.

Besides the usual cultures grown in Buchner tubes or in Novy jars, inoculations were made in a variety of media in long test tubes, 20 $\mathrm{cm}$. in length and $1.25 \mathrm{~cm}$. in diameter, the type used by Noguchi for the cultivation of spirochætae.

The tubes were inoculated with saline emulsions of the organism, incubated at $37 \mathrm{C}$., and observed for twenty days. The agar, of 2 percent concentration, was made up with Liebig's extract, the acidity varying from 0.9 to 1.1 percent. The broth was similarly made up with beef extract and was of an acidity of 1.1 percent. Twenty cubic centimeters of agar or broth were used in each tube. The quality and proportion of the serum used were the same as that previously described. The tissue employed in some of the media consisted of pieces of rabbit kidney, the sterility being tested by incubation in plain broth for three days prior to use. Over some of the media a layer of about 2.5 c.c. of liquid petrolatum was used. 
Table 1 shows the results obtained with the various media. A (lescription of the results of these studies, which were made soon after the isolation of the organism, follows.

TABLE 1

Results of Cultivations in Various Media in Deep Tubes

\begin{tabular}{|c|c|c|c|c|c|c|c|}
\hline Agar & No growth & No growth & No growth & No growth & No growth & No growth & No growth \\
\hline $\begin{array}{l}\text { Two percent } \\
\text { glucose agar }\end{array}$ & No growth & No growth & $\begin{array}{l}\text { Slight } \\
\text { growth }\end{array}$ & $\underset{\text { growth }}{\text { Slight }}$ & Growth & Growth & Growth \\
\hline $\begin{array}{c}\text { Sugar-free } \\
\text { broth }\end{array}$ & No growth & No growth & No growth & No growth & No growth & No growth & No growth \\
\hline $\begin{array}{l}\text { Two percent } \\
\text { glucose broth }\end{array}$ & $\begin{array}{l}\text { Very slight } \\
\text { growth }\end{array}$ & $\begin{array}{l}\text { Slight } \\
\text { growth }\end{array}$ & $\begin{array}{l}\text { Slight } \\
\text { growth }\end{array}$ & $\begin{array}{l}\text { Slight } \\
\text { growth }\end{array}$ & $\begin{array}{l}\text { Slight } \\
\text { growth }\end{array}$ & $\begin{array}{l}\text { Slight } \\
\text { growth }\end{array}$ & $\begin{array}{l}\text { Slight } \\
\text { growth }\end{array}$ \\
\hline
\end{tabular}

Cultures in Deep Tubes.-The growths are described after fourday observations. Negative tubes were observed twenty days.

Agar: No growth appears in any of the media.

Glucose agar, 0.5 percent: With kidney tissue, after forty-eight to seventy-two hours, a slight growth appears about the tissue in the form of minute, white flocculi; with ascitic fluid, a more marked growth appears, extending up into the medium to within two and onehalf centimeters from the top. Precipitation occurs after the growth becomes profuse. There is no odor evident in this, or any other medium.

Glucose agar, 2 percent: The same characteristics are observed as in the 0.5 percent medium, except that the growth is more profuse.

Sugar-free broth: No growth is found in any of the media. Indol tests, therefore, could not be made.

Glucose broth, 2 percent: After eight days, the growth appears as minute flocculi at the bottom of the tube with a tendency to grow up the side of the tube. The medium remains clear above the growth. No pellicle is formed.

Cultures in Buchner Tubes.-Agar: No growth appears.

Glucose agar, 0.5 and 2 percent: No growth appears. 
Glucose serum agar, 0.5 and 2 percent (three parts agar, one part ascitic fluid): After three days a creamy white growth is observed with no tendency to spread over the surface but rather to heap up. The growth may occasionally take on a very light-brownish color in old cultures. There is a moderate amount of precipitation. After five days, the growth is more profuse and precipitation more marked. In subcultures, the precipitation becomes still more marked.

Potato: After four days, an invisible, whitish growth is found, demonstrable by scraping the medium.

Gelatin, 15 percent: No growth is found even in thermostat.

Litmus milk: A slight amount of acidity is observed after eighteen days.

Loeffler's medium: A very slight growth is observed.

Fermentation Reactions. - The fermentation reactions were tested by inoculation of tubes of serum agar containing various carbohydrates. It has been shown by Libman, Celler, and Sophian* that the optimal media for determining acid production are serum carbohydrate media, both fluid (broth) and solid (agar), the broth media being better for investigation of the pneumococcus-streptococcus group which they particularly studied. For the investigation of the typhus bacillus, it was decided to use the solid media because growth was found to be better on them.

The media were made up of agar of a 3 percent concentration, containing 2 percent of the various carbohydrates, to which was added one-third as much ascitic fluid (specific gravity of 1013 or over). The medium was tinged with litmus (Kahlbaum). The carbohydrates used were chemically pure glucose, lactose, saccharose, maltose, mannite, lactose (all Merck's chemicals), arabinose, inulin, raffinose, galactose, and dextrin (prepared by Kahlbaum). The studies were made with agar of which the acidity was 1 and 1.5 percent. Acid production and precipitation occurred just as often in the 1 percent medium, and so in the identification of organisms later isolated, only the 1 percent medium was employed. Surface inoculations were made, the tubes then being placed in Buchner tubes and observed after six days' incubation in the thermostat. It was found important to inoculate a fair amount of culture. All experiments were made in quadruplicate.

* Read at the meeting of the Association of Ancrican Pathologists and Bacteriologists, April, 1914; not yet published. 
There were studied at first three strains of the bacillus obtained from epidemic cases, and one from an endemic case. Table 2 shows the results after six days' incubation.

These observations show clearly that the bacillus produces acid from glucose, maltose, galactose, and inulin, and does not produce acid from raffinose, mannite, arabinose, saccharose, dextrin, and lactose. Visible gas is not produced from any of these carbohydrates.

After these preliminary studies were made, a number of organisms subsequently isolated from typhus cases, or from experimental animals, were investigated in a similar fashion, and the fermentation reactions were found to be identical with those just detailed. Later in the work, organisms were identified by their reaction in all these carbohydrates, except mannite, dextrin, and arabinose. The fact that the organisms from the endemic cases differed in no way from those from the epidemic cases, is of great importance.

TABLE 2

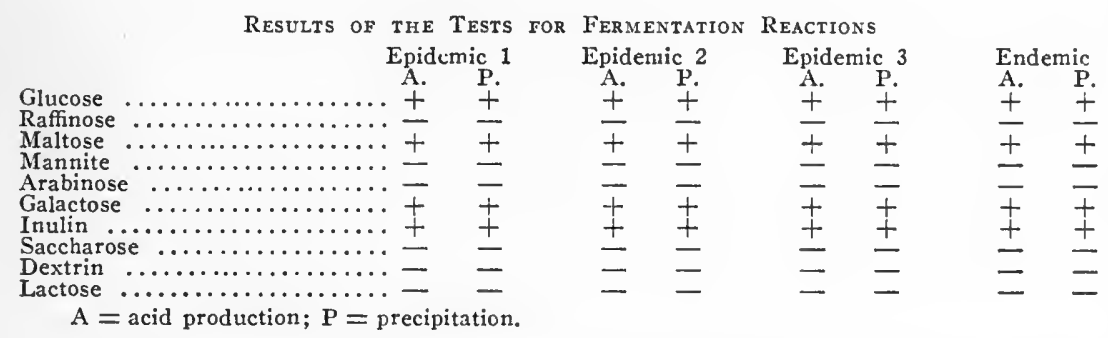

Colonies on Plates.-Plates were poured from a saline suspension of the organism and grown in Novy jars at 37.5 C. The media used were agar, glucose agar, and serum glucose agar. Colonies were obtained only in serum glucose agar, appearing after seven days. Only once did surface colonies develop.

The surface colonies measured from 1.5 to $2 \mathrm{~mm}$. in diameter. They were round, oval, or oblong, projecting almost $1 \mathrm{~mm}$. above the surface, each colony surrounded by a zone of fine, dust-like dots, located in an area of precipitation. The color by reflected light was light cream; by transmitted light, the colonies were opaque. Microscopically (No. 6 objective and No. 4 eyepiece), the colonies appeared as opaque bodies with fading, irregular contour. The granules in the surrounding zone were irregular in form, or spherical with refractive contour, and were more numerous close to the colony. 
The colonies just beneath the surface measured $1 \mathrm{~mm}$. in diameter, were round, oblong, or triangular in shape, and of a light cream color. Around each colony there was a zone of precipitation, in which were localized fine, opaque granules.

The deep colonies varied in size from pin-point to $1 \mathrm{~mm}$. in diameter. They were round, oval, or triangular, the last type predominating. Microscopically, the colonies were triangular, or acornshaped, sharply circumscribed with irregular contour.

From a study of the foregoing facts, the following deductions are made regarding the growth of the organism described: The organism grows much better in solid than in fluid media; in solid media it requires carbohydrate and serum; the optimal medium in the studies thus far made is 2 percent glucose serum agar. For keeping the organism alive, however, the 0.5 percent glucose serum agar was used, as the larger glucose content was presumed to decrease virulence to a greater extent.

Aerobic Studies.-This organism is an obligatory anaerobe. It was at first thought that slight growth had occurred aerobically, after anaerobic cultivation. This was due to the fact that a large amount of growth had been carried over in transplanting and was mistaken for further growth. Subsequent observations demonstrated that no increase in growth had occurred on the slants. Moreover, the material on the slants could not be further subcultured aerobically. Every time a culture was made from the original colony, two slants of 0.5 percent glucose serum agar were inoculated with portions of the growth. These tubes were observed for twenty days and no growth was ever noted. Subsequently, many strains of the organism were transplanted on the following media and kept under aerobic conditions, always with negative results: 0.5 percent glucose serum agar, 2 percent glucose serum agar, 2 percent glucose serum agar plus human blood, Loeffler's medium, Dorset egg medium.

Thermal Death Point.-This was found to be a temperature of $55 \mathrm{C}$., for ten minutes, a result which coincides with the results obtained by Anderson and Goldberger ${ }^{16}$ for the thermal death point of the virus in typhus blood.

Filtration Experiments.-After the isolation of the typhus bacillus, its filtrability was determined as follows: Two cubic centimeters of sterile, distilled water were added to each of several slants 
of a seven-day growth of the organism. The growth was then scraped off the surface of the medium, care being taken not to remove any of the agar. This milky emulsion was again diluted with the same amount of sterile, distilled water and passed through a Berkefeld filter, size $N$. The filtrate was then inoculated on slants of 0.5 percent glucose serum agar, which were placed in Buchner tubes. Control tubes, made from the unfiltered emulsion of the organism, were similarly inoculated on slants of 0.5 percent glucose serum agar. In no instance did tubes inoculated from the filtrate show any growth, whereas all the controls grew in the usual manner. This agrees then with the fact that the virus in the blood is non-filtrable.

\section{GENERAL RESULTS OF THE BLOOD CULTURES}

Epidemic Cases.-Blood cultures were made in seven cases of epidemic typhus fever during the febrile stage of the disease (Tables 3 and 4). In every case studied, the bacillus was isolated in pure culture. From an eighth case, blood was inoculated intraperitoneally into two guinea-pigs, and after an incubation period they developed a typical febrile reaction. During the height of the reaction, blood obtained by cardiac puncture was found to contain the organism.

Endemic Cases.-Blood cultures were made in thirty-seven endemic cases. In thirty-four, the cultures were made at varying times during the course of the disease up to and including the day of crisis. Eighteen of these, or 53 percent, yielded the bacillus. A higher percentage of positive results would probably have been obtained, if a rich ascitic fluid had been available for use in each case.

Blood Cultures After the Crisis.-Blood cultures were made after the crisis in six of the cases of epidemic typhus fever, and all proved negative. Three of these had already been cultured during the febrile period of the disease and the organism recovered. These were Cases $2,4,5,7,8$, and 9 , and the post-critical cultures were made between the thirteenth and sixteenth days.

Nine of the endemic cases were cultured after the crisis. Two of them yielded the bacillus, the one twelve, and the other, thirty-six, hours after the crisis. These results are of great interest in view of the fact that it has been shown by Anderson and Goldberger, ${ }^{16}$ and by ourselves (see experimental studies), that the blood of an infected animal is still infectious thirty-two hours after the crisis. 
TABLE 3

Cultural Results in Epidemic Typhus Cases

\begin{tabular}{|c|c|c|c|c|}
\hline $\begin{array}{c}\text { Number } \\
\text { Case }\end{array}$ & Time of Culture & $\begin{array}{l}\text { Days after Culture } \\
\text { When Positive*" }\end{array}$ & $\begin{array}{c}\text { Amount of } \\
\text { Blood } \\
\text { Cultured }\end{array}$ & $\begin{array}{c}\text { Number of } \\
\text { Colonies } \\
\text { Found }\end{array}$ \\
\hline $\begin{array}{r}1 \\
2 \\
3 \\
4 \\
5 \\
6 \\
7 \\
8 \\
9 \\
10 \\
11\end{array}$ & $\begin{array}{r}36 \text { hours before } \\
4 \text { days before } \\
6 \text { days before } \\
41 / 2 \text { days before } \\
31 / 2 \text { days before } \\
\text { At crisis } \\
13 \text { days after } \\
16 \text { days after } \\
13 \text { days after } \\
\text { At crisis } \\
4 \text { days before }\end{array}$ & $\begin{array}{c}7,9,10 \\
3,3 \\
4,5 \\
5,6,8 \\
3,5,5 \\
\text { Negative } \\
\text { Negative } \\
\text { Negative } \\
\text { Contaminated } \\
7,10,16\end{array}$ & 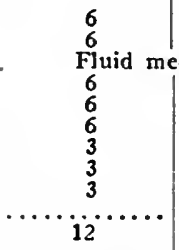 & 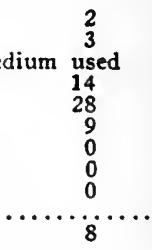 \\
\hline
\end{tabular}

- This is reckoned back from the crisis, or, if there was not a typical crisis, the time when the temperature first reached $100 \mathrm{~F}$. $(38 \mathrm{C}$.).

* The second and third figures refer to the later appearing colonies.

TABLE 4

Cultural Restlts in Endemic Typhus Cases

\begin{tabular}{|c|c|c|c|c|}
\hline $\begin{array}{l}\text { Case } \\
\text { Number }\end{array}$ & Time of Culture & $\begin{array}{l}\text { Days after Culture } \\
\text { When Positive }\end{array}$ & $\begin{array}{c}\text { Amount of } \\
\text { Blood } \\
\text { Cultured }\end{array}$ & $\begin{array}{c}\text { Number of } \\
\text { Colonies } \\
\text { Found }\end{array}$ \\
\hline $\begin{array}{r}1 \\
2 \\
3 \\
4 \\
5 \\
6 \\
7 \\
8 \\
9 \\
10 \\
11 \\
12 \\
13 \\
14 \\
15 \\
16 \\
17 \\
18 \\
19 \\
20 \\
21 \\
22 \\
23 \\
24 \\
25 \\
26 \\
27 \\
28 \\
29 \\
30 \\
31 \\
32 \\
33 \\
34 \\
35 \\
36 \\
37 \\
38 \\
39 \\
40\end{array}$ & $\begin{array}{r}26 \text { hours before } \\
12 \text { hours before } \\
41 / 2 \text { days before } \\
4 \text { days before } \\
31 / 2 \text { days before } \\
36 \text { hours after } \\
36 \text { hours after } \\
4 \text { days before } \\
12 \text { hours after } \\
60 \text { hours before } \\
16 \text { hours before } \\
36 \text { hours before } \\
48 \text { hours before } \\
60 \text { hours before } \\
31 / 2 \text { days before } \\
\text { Day of crisis } \\
31 / 2 \text { days before } \\
24 \text { hours before } \\
\text { Day of crisis } \\
48 \text { hours before } \\
60 \text { hours before } \\
12 \text { hours before } \\
10 \text { hours before } \\
\text { No culture } \\
36 \text { hours before } \\
4 \text { days before } \\
4 \text { days before } \\
4 \text { days before } \\
\text { No culture } \\
3 \text { days before } \\
\text { Day of crisis } \\
8 \text { hours before } \\
5 \text { days before } \\
5 \text { days before } \\
\text { No culture } \\
\text { Day of crisis } \\
48 \text { hours before } \\
24 \text { hours before } \\
24 \text { hours before } \\
5 \text { days before }\end{array}$ & $\begin{array}{c}3 \\
4 \\
4 \\
3 \\
6 \\
\text { Negative } \\
8 \\
\text { Negative } \\
14 \\
7 \\
\text { Negative } \\
\text { Negative } \\
9 \\
\text { Negative } \\
\text { Negative } \\
9 \\
\text { Negative } \\
9 \\
\text { Negative } \\
10,11 \\
\text { Negative } \\
\text { Negative } \\
11 \\
\text { Negative } \\
\text { Negative } \\
\text { Negative } \\
\text { Negative } \\
\text { Negative } \\
\text { Negative } \\
11 \\
11 \\
9 \\
9,10 \\
\text { Negative } \\
7,8 \\
8 \\
10 \\
\text { Neg }\end{array}$ & 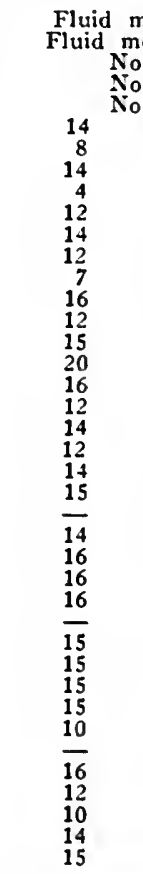 & 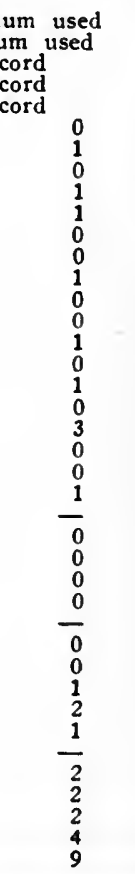 \\
\hline
\end{tabular}




\section{Results cf Anaerobic Cultures in Control Cases}

With the identical technic used for isolating the bacillus just described from individuals with typhus fever, anaerobic blood cultures were made in 198 febrile cases. The ascitic fluids used in these cases were the same as those employed in the typhus cultures. These cases represented a variety of conditions, such as typhoid fever, tuberculosis, acute osteomyelitis, acute rheumatic endocarditis, subacute bacterial endocarditis, chorea, acute nephritis, influenza, liver abscess, acute cholangeitis, erysipelas, phlebitis, splenic anemia, post-partum infection, etc. In none of these 198 cases was an organism recovered which in any way resembled the bacillus isolated from the cases of typhus fever.

THE IDENTITY OF THE ORGANISMS ISOLATED FROM VARIOUS SOURCES

The organisms isolated from the cases of endemic typhus were found to be culturally identical with those isolated from cases of epidemic typhus. Careful studies were made in order to determine whether any small cultural differences could be detected, such as exist, for example, between the typhoid and paratyphoid bacilli. In no instance was the slightest variation observed in their behavior on any of the media.

Similarly, the organisms isolated by blood culture from eight guinea-pigs and one monkey (virus obtained from Anderson and Goldberger), in which the disease had been produced experimentally, were studied. All of them were found to possess the same cultural characteristics as those isolated from the human cases of typhus fever. The importance of the proof of the identity of the organisms isolated from epidemic, endemic, and experimental typhus fever is self-evident.

\section{PERIOD OF MOST MARKED BACTERIEMIA}

In most of the cases studied, it was impossible from the history to determine the exact date of onset of the illness. In estimating at what period of the disease the blood cultures were taken, it was therefore necessary to reckon backwards from the date of termination of the disease. The day of the crisis, or in the absence of a crisis, the day on which the temperature first reached $100 \mathrm{~F}$. (38 C.) and remained at about that figure, was always considered as the last day of the disease. By adding together all the amounts of blood used for cultures made within three days before the crisis, and those made on the 
fourth and fifth days before the crisis, and comparing these figures with the number of colonies found at the same times, it seems that the organism occurs more abundantly in the blood on the fourth and. fifth than on the few days immediately preceding the crisis. It will be of great interest to make further studies in this connection, because in the cultures taken from the inoculated animals the organisms were found most frequently early in the disease. Therefore it may be found that blood cultures taken in the first few days of the disease in man may show the largest number of organisms.

RELATION OF THE DEGREE OF THE BACTERIEMIA TO THE SEVERITY OF THE CASES

A calculation of the total amount of blood used in all cultures made on or before the day of crisis in the epidemic and in the endemic cases gives the following result: In epidemic cases, 51 c.c. of blood were used and 74 colonies found; in endemic cases, 436 c.c. of blood were used and 33 colonies found. Therefore, in the cases which I have studied, the bacillus was found eighteen times as abundantly in the blood of the epidemic, as in the blood of the endemic cases. Without laying too much stress on this exact figure, it is very evident that the bacteriemia is more intense in the epidemic, than in the endemic cases. This difference in the number of bacteria in the blood may be one of the reasons for the marked difference in the severity of the two varieties of the disease.

The figures for the numbers of organisms found in the positive cultures and of the amount of blood used can be seen in Tables 3 and 4. It will be noted that in the two cases of epidemic typhus fever which had the most marked bacteriemia, the figures show that there were present in a cubic centimeter of blood, two and one-third, and four and two-thirds colonies, respectively. Both of these cases were iatal.

\section{DIAGNOSTIC VALUE OF BLOOD CULTURES}

Because of the late maturation of the colonies, the results of the blood cultures are usually only known after the termination of the illness. But it is nevertheless of value, for confirming the clinical diagnosis. In fact, in 87.5 percent of fifty-one cases studied, the clinical diagnosis was confirmed by blood culture, agglutination, or complement-fixation tests. 
On the other hand, in two cases in which the diagnosis had been overlooked, the positive blood culture first called attention to the nature of the condition. In both cases, the temperature which had been high on admission, fell suddenly to normal within twelve hours. The subsequent convalescence was uneventful and a tentative diagnosis of influenza had been made. After the results of the blood cultures were reported, a more careful investigation revealed the fact that both individuals had passed through an illness with the typical symptoms of typhus fever. The sudden drop in temperature immediately after admission undoubtedly represented the crisis.

It is quite probable, therefore, that similar cases of typhus fever, which are only recognized toward the very end of the illness, are not infrequently wrongly interpreted.

\section{CONCLUSLONS}

Attention has been drawn to the fact that the virus of typhus fever circulates in the blood of an infected person or animal, that the virus is not filtrable and, therefore, is of microscopic size, and that aerobic cultures made with a great variety of media are negative. Hence, it was considered plausible that the infective agent is an anaerobic organism. By means of an anaerobic method of blood culture, a bacillus was isolated in pure culture from seven cases of European epidemic typhus fever, or 100 percent of the cases studied during the febrile period. With the same method, the identical organism was recovered during the febrile period of the local endemic form of the disease in eighteen of thirty-four cases, or 53 percent, and in two additional cases taken after the crisis. Similar blood cultures made in 198 control cases yielded no such organism.

Considered in conjunction, with the serologic and experimental evidence which follows, these facts prove that this bacillus is the etiologic factor in typhus exanthematicus.

At the very kind suggestion of Professor William $\mathrm{H}$. Welch, it has been deemed advisable to name the organism, Bacillus typhiexanthematici. The name Bacillus typhi exanthematici was applied by $\mathrm{Klebs}^{63}$ in 1881 to a hypothetical organism in typhus fever. The name was never actually used, as the search for the organism proved futile. The hyphenating of "typhi" and "exanthematici" succeeds in giving us a binomial designation properly descriptive. 


\section{SEROLOGIC STUDIES* \\ Peter K. Olitsky}

The typhus bacillus, being an obligatory anaerobic organism, can not be studied with the same ease as aerobic bacteria. Hence it was necessary to modify the usual serologic methods in order to overcome certain difficulties. Indeed, the study of some reactions was restricted by the inapplicability of any method. Furthermore, at the inception of this work, two organisms were under consideration, one having been isolated from the blood of patients suffering from endemic typhtis fever (Brill's disease), and the other, from the blood of individuals with epidemic (European) typhus fever. The serologic investigations demonstrated early in the course of the work that these two conditions are identical, and, what is still more important, they have definitely associated the organism with the etiology of typhus fever.

I shall discuss the various phases of this work in the following order: (1) complement fixation, (2) agglutination, (3) precipitation. (4) other antibody actions, (5) the identity of the organism obtained from endemic typhus fever with that isolated from epidemic typhus fever, (6) serologic studies in animals, (7) serologic reactions in individuals after exposure to typhus fever, (8) the relation between the serologic results and typhus fever.

\section{COMPLEMENT FIXATION IN TYPHUS FEVER}

Attempts have been made, even before a definite organism was associated with typhus fever, to study the fixation of complement in this disease. Cathoire, ${ }^{33}$ in 1910, obtained positive reactions in typhus fever, employing as antigen alcoholic extracts of spleen tissue from a case of the disease. Likewise Markl, ${ }^{78}$ using extracts of organs (spleen, liver, lung, and heart) from cases of typhus fever, obtained distinct inhibition, altho not complete fixation, with sera from this disease. Upon analyzing these results, one must consider the non-specificity of the results. Alcoholic extracts of tissue. will yield a lipoid antigen. Such, if carefully titrated, will bind complement in the presence of "lipoidophilic" substances (as are found in the blood in syphilis). It makes little difference whether the organs are obtained from diseased or healthy subjects. Hence, there

* This work was done under the tenure of the Eugene Meyer, Jr., Fellowship. 
is no relation between such results and the etiology of typhus fever. The question as to whether syphilis is present at the same time must be considered when complete fixation is found by the use of these methods. In the same category may be placed the results of Jablons, ${ }^{60}$ who found that a lipoid antigen gave positive results in several cases of typhus fever. Here again the question of syphilis being concomitantly present, must be considered.

My own work does not bear out these results. With a pure lipoid (Noguchi) antigen or with alcoholic extracts of guinea-pig hearts, absolutely negative results were obtained in eleven cases of epidemic typhus fever and eight cases of endemic typhus. (Some of these tests were made by Dr. David J. Kaliski, of the Mount Sinai Hospital.) We must conclude that the results obtained with lipoid antigens have no bearing upon the causative factor in typhus fever.

The results of my work are based upon the principle of specificity. Given an organism, such as the typhus bacillus, I have determined the presence of complement-fixing antibodies against this bacterium only in typhus fever, not in other conditions.

In describing the methods used, I shall state in detail only such procedures as my experience has led me to adopt.

\section{METHOD}

The Antigen.-There are several factors which should be emphasized in the preparation of the typhus antigen.

(1) Aqueous extraction is superior to saline. Autolysis, after heating, for twenty-four hours, gives a much better extract.

(2 Because of the fact that they are more easily extracted, older cultures are preferable to those more recently isolated.

(3) Antigens should have a long "range," i. e., the anticomplementary unit should be at least four times the amount used in the test. The antigenic property should be determined by titrating with immune serum.

(4) Filtrates but not suspensions of organisms are preferable. The latter are unstable, and vary in titer from time to time. Bacterial bodies per se have a tendency to absorb complement, hence the danger of non-specific reactions. Besides, suspensions are usually too anticomplementary and too little antigenic.

The method of preparing antigen is as follows: Since this organism is an obligatory anaerobe, there is no method for growing it in large bulk. The growth on a 0.5 percent glucose serum agar slant (grown 4-5 days in a Buchner tube) is washed off with 1 c.c. of sterile, distilled water. Care is taken that none of the media is transferred to the water, and each culture used is carefully examined as to its purity with a gram stain. Twenty to thirty such slants give an amount of extract sufficient for all practical needs (10-15 c.c. extract). The turbid suspension is then heated to $60 \mathrm{C}$. for one hour and then autolyzed at 37 C. for twenty-four hours. Through a sterile Berkefeld filter, size N, 
which has been previously digested and cleaned out, this turbid fluid is filtered. The filtration should be slow, otherwise the extract becomes contaminated on standing, or anticomplementary as the result of the presence of bacterial bodies. No preservative is added to the resultant extract. The antigen keeps for months if, when it is first made, it is heated at $56 \mathrm{C}$. for one-half hour on each of three consecutive days. For titrating or use, it is "normalized" by the addition of nine parts of antigen to one part of 0.85 percent saline.

The "antigenic" value of the antigen is determined as follows: The antigen is first titrated for its anticomplementary unit. In this respect, the titrations of most antigens are straight (undiluted), 1:5 or 1:10. An antigen diluted $1: 5$ is very safe to use. One-fourth of the anticomplementary unit is titrated with decreasing amounts of rabbit immune serum, starting at 0.1 c.c. A good antigen should give complete inhibition of hemolysis with amounts of serum less than 0.005 c.c. and no inhibition with human normal serum.

The rabbit immune serum is obtained by intravenous injection of a rabbit at four-day intervals with increasing amounts of typhus culture. The initial dose amounts to the saline suspension of the growth on one slant; the last injection is equivalent to the growth on four slants. The animal is bled 9-10 days after the last injection (v. infra).

Antigen 11-9, for example, was titrated for its anticomplementary unit. There was incomplete hemolysis in 0.1 c.c. Upon dilution $1: 5$ complete hemolysis was obtained in 0.4 c.c., complete inhibition in 0.6 c.c. Titrating 0.1 c.c. of a $1: 5$ dilution with rabbit immune serum showed complete binding of complement with 0.002 c.c. of the rabbit serum. Such an antigen was regarded as trustworthy.

The Hemolytic System.-Complement is prepared by diluting fresh guineapig serum 1:10. This is titrated against constant amounts of amboceptor. The amount used is ordinarily 0.3 c.c. The amboceptor consists of anti-sheep cells rabbit serum. The titer is usually above 1:1000. Washed sheep cells, 5 percent suspension, employing 0.5 c.c., completes the hemolytic system. In general, the hemolytic system must be very active if clear-cut results are to be obtained. This system (which is used with success by Dr. David J. Kaliski for routine Wassermann tests) is gauged so that complete hemolysis occurs in fifteen minutes. It represents one-half the quantities recommended by Wassermann for his test.

The Patient's Serum.-Inactivated (56 C. for one-half hour) serum is used in amounts of 0.05 c.c. and 0.1 c.c. Serum that gives complete fixation in both amounts is regarded as $t+++$; in only the larger amount as $t+$ or +++ . Such positive sera hold their antibody content for over one month if kept cold.

The Test.-Each test consists of a known positive and a known negative serum, as well as the serum itself, and antigen (twice the amount used in the test) as controls. Fixation is allowed for one-half hour at $37 \mathrm{C}$., and three and one-half hours in the ice box. Readings are made when the serum and antigen controls are completely hemolyzed.

Complement Fixation During the Course of Typhus Fever.These methods were applied in the study of typhus fever. In the beginning, three antigens were used: one made up of the epidemic 
typhus organisms; one, of the organisms from endemic cases; and a third, of a mixture of both organisms. Upon comparing the results obtained in one case of endemic typhus and eleven cases of epidemic typhus fever, we find that the endemic case gave a ++++ reaction with an epidemic typhus organism, but a negative one with an endemic typhus organism. There may be grounds for this in that, at that time, we had only one strain of endemic typhus organism on hand, but four strains of epidemic typhus organisms. It is well known that polyvaient antigens almost always give stronger reactions than monovalent.

Of the eleven cases of epidemic typhus fever, nine were tested after the crisis; two of these gave negative reactions to endemic, as well as epidemic typhus organism antigen, while seven were positive with either one or the other of three antigens (Table 1). The relations of these antigens to each other we shall discuss in another place.

TABLE 1

The Reactions in Endemic Typhus Fever and Epidemic Typhus Fever Towards Individual Antigens

\begin{tabular}{|c|c|c|c|c|}
\hline \multirow{2}{*}{ Case } & \multirow{2}{*}{$\begin{array}{c}\text { Days After } \\
\text { Crisis }\end{array}$} & \multicolumn{2}{|c|}{$\neg$-Individual Antigens $\neg$} & \multirow[b]{2}{*}{ Mixed } \\
\hline & & $\begin{array}{l}\text { Epidemic } \\
\text { Typhus }\end{array}$ & $\begin{array}{l}\text { Endemic } \\
\text { Typhus }\end{array}$ & \\
\hline 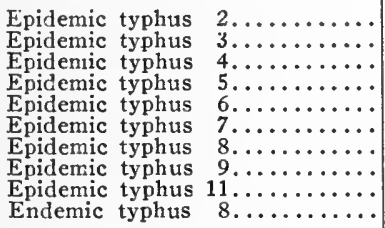 & $\begin{array}{l}5 \\
3 \\
3 \\
3 \\
4 \\
9 \\
3 \\
5 \\
3 \\
4 \\
6 \\
6\end{array}$ & $\begin{array}{l}\text { Negative } \\
++++ \\
++ \\
\text { Negative } \\
\text { Negative } \\
++ \\
++ \\
\text { Negative } \\
\text { Negative } \\
++++\end{array}$ & $\begin{array}{l}++ \\
+++ \\
++ \\
\text { Negative } \\
\text { Negative } \\
++ \\
++ \\
\text { Negative } \\
\text { Negative } \\
\text { Negative }\end{array}$ & $\begin{array}{c}++ \\
+++ \\
++ \\
\text { Negative } \\
\text { Negative } \\
++ \\
++ \\
++ \\
\text { Negative } \\
\text { Negative }\end{array}$ \\
\hline
\end{tabular}

After this, we discarded these single antigens and employed one containing both strains of the typhus bacillus. Undoubtedly because of this, as well as of the fact that we acquired more strains of the organism, our results since then have been more uniform and our positive reactions more common.

Including the series mentioned, eleven cases of epidemic and thirtyfour of endemic typhus fever were tested. Nine of the epidemic and thirty of the endemic cases were tested after the crisis. During this apyrexial period, the total number of positives was twenty-eight, or 71.8 percent. Of all the cases tested, irrespective of the stage of 
the disease, the total number of positives was twenty-nine, or 64.4 percent. This is a rather low percentage, but one must consider that on account of the nature of the work, namely, determining whether this bacillus is the cause of typhus fever, only definitely positive results were accepted, one plus or doubtful reactions being regarded as negative. Furthermore, there may be a possibility of refining the antigen so that it can react with lesser amounts of antibody. However, in comparison with other bacterial diseases where complement fixation occurs, e. g., glanders or gonorrhea, the results are very favorable.

TABLE 2

The Relation Betweex Conplesient Fixation and tife Stace of the Disease

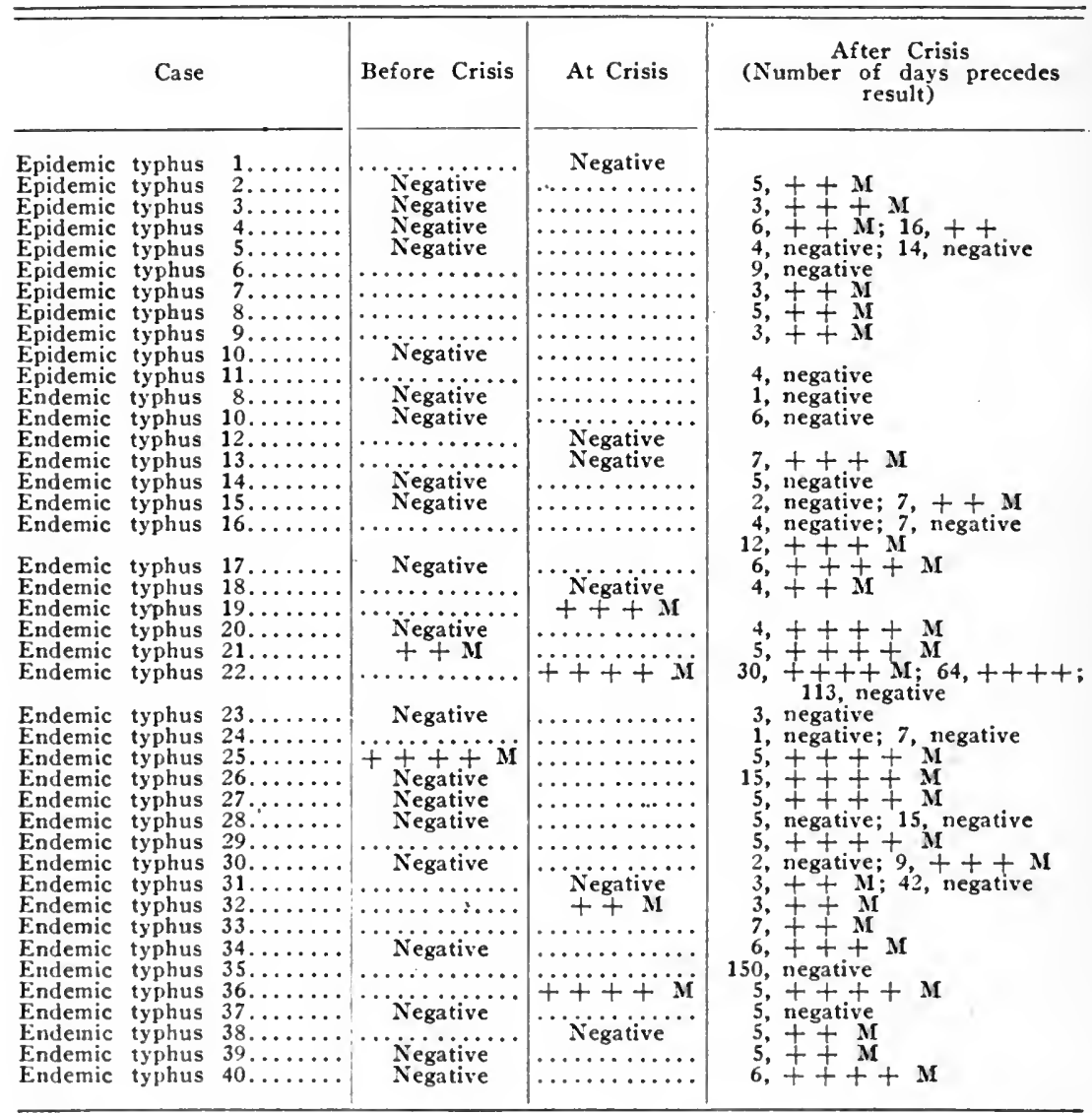

$\mathbf{M}=$ mixed epidemic and endemic typhus bacilli antigen. 
In regard to the stage of the disease in which positive reactions occur, remarkable observations were made. Twenty-five cases were tested at the height of the disease. Of these only two were positive, one a ++ reaction, the other $a++++$. Both were tested one day before the crisis. The latter case had a negative, the former a positive blood culture.

Ten cases were tested at the crisis. Of these, two gave ++++ reactions, one $\mathrm{a}+++$, one $\mathrm{a}++$, and the rest were negative. Thus we see a tendency towards an increased number of complementfixing bodies at the crisis.

In the post-critical stage of the disease, the positive reactions are more common. In looking through Table 2 , one will be struck by their number. Indeed, 71.8 percent are positive here, as was mentioned. One may trace the development in an individual case of a negative reaction at the height of the disease to $\mathrm{a}++++$ reaction after the crisis.

It will be seen from this table that the complement-fixing antibodies reach their maximal concentration between the second and twelfth days after the crisis (endemic typhus Cases 15, 16, and 30). Their persistence has been studied in endemic typhus Case 22 (through the kindness of Dr. J. Reiss), in which a previously ++++ reaction became negative between 64 and 113 days after the crisis, and in endemic typhus Case 31, in which there was a positive reaction three days after the crisis that was found to have disappeared thirty-nine days later. In one case, in which a diagnosis of typhus fever occurring five months previously was made on the patient's history, the reaction was negative (endemic typhus Case 35 ).

Complement Fixation in Control Cases.--In these studies, that most important fact in bacterial complement-fixation work was always kept in mind: The sum of the anticomplementary properties of antigen and serum, when mixed in a test, is greater than the sum of the anticomplementary activities of each by itself. Altho the reagents employed were of such degree of delicacy as to eliminate errors arising from anticomplementary action, the element of specificity was further enhanced by our considering such tests as gave a doubtful $( \pm)$ or one plus reaction, negative. In fact, even such degree of reaction is regarded as negative for diagnosis in a Wassermann test based on one to four plus readings. This being the case, we may 
safely say that all our non-typhus control cases gave negative reactions. (The great majority gave absolutely complete hemolysis; a few, a faint trace of inhibition in larger amounts of serum.)

In all there were 104 control cases. These covered a great variety of pathologic conditions: acute febrile diseases such as typhoid fever, paratyphoid fever, influenza; chronic infectious processes such as lues, tuberculosis; new growths, surgical conditions, etc. In several of the acute febrile diseases in which the serum was tested during the febrile stage, a second test was made with the blood taken at some time in the apyrexial state. In all such instances, the results were likewise negative.

Complement Fixation in Typhus Fever Cases With Other Than Typhus Antigens.-As is known to serologists, certain sera, in the presence of any bacterial antigen, will bind complement. These reactions are absolutely non-specific, and one of the best examples we have is that of rabbit serum in large amounts. To avoid this element of non-specificity, the typhus antigen was titrated with normal, as well as with immune serum. Again, the typhus fever serum which gave positive results with typhus antigen was tested with the following bacterial antigens, the results being absolutely negative: Antigens made of Bacterium coli, Staphylococcus aureus, gonococcus, streptococcus (single antigens made of various types), and of some grampositive, anaerobic bacilli having a morphology similar to that of the typhus bacillus (Bacillus acnes and bacilli isolated from ascitic fluid and from rabbit kidney). These antigens were prepared in the same manner as the typhus antigen.

We shall discuss later the relation of the results in complement fixation to other serologic results in typhus fever, as well as their significance in this disease.

\section{AGgLUTINATION IN TYPHUS FEVER}

The method of choice for performing the agglutination tests with typhus serum, or with the typhus organism, is the microscopic. This method is so well controlled that it equals the macroscopic for scientific accuracy. The reasons for employing the microscopic method rather than the macroscopic are these:

(1) The organism grows rather sparsely and requires strict anaerobic conditions; hence the large quantities necessary for suspensions as agglutinogens, are extremely difficult to obtain.

(2) The bacillus, without the addition of serum, has a marked tendency to clump on standing, making a twenty-four or forty-eight hour method impractical. 
(3) On making comparative studies between the microscopic and macroscopic methods, we find that wherever we obtain a positive reaction with the former, we likewise obtain a positive result with the latter. Important to note is the fact that the macroscopic tests usually give positive readings in much higher dilutions than do the microscopic. Proagglutinoid zones are common in the former and indeed the clumping is best seen beyond the dilutions of $1: 200$, while proagglutinoid zones in the latter are never seen and the average limit of clumping is about $1: 200$,

(4) Furthermore, this method conserves the supply of serum, which at best is always limited in amount and which is needed for so many other studies.

The microscopic method which we apply consists in setting up a series of small test tubes, each containing an increasing dilution of the serum to be tested. Five tubes are ordinarily used. Tube 1 contains 0.1 c.c. of serum with 0.9 c.c. of 0.85 percent salt solution; Tube 2 contains 0.5 c.c. of the thoroughly mixed contents of Tube 1 plus 0.75 c.c. saline; Tube $3,0.5$ c.c. of contents of Tube 2 plus 0.5 c.c. saline; Tube 4 contains 0.5 c.c. of contents of Tube 3 plus 0.5 c.c. saline and Tube $5,0.5$ c.c. of contents of Tube 4 with 0.5 c.c. saline. Thus accurate dilutions (each in a test tube) of $1: 10,1: 25,1: 50,1: 100$, and $1: 200$ are made. The serum used is inactivated at $56 \mathrm{C}$. for one-half hour.

The agglutinogen is made by suspending the growths of several strains of typhus bacilli in saline solution. This is then shaken, either by hand or in the shaking machine, until the clumps are thoroughly broken up. It is then centrifugated gently for a short time so as to clear the suspension of any small masses or clumps. The accuracy of the final dilution (that of the serum mixed with agglutinogen) is maintained by using the same loop for each of these reagents and taking off a drop from the surface of each fluid. In this way the final dilutions of $1: 20,1: 50,1: 100,1: 200$, and $1: 400$ are made.

The tests are read at the end of one hour at room temperature. When all the bacteria are clumped together into solid masses with clear spaces between such clumps, the reaction is called ++ ; when the clumps are definite, but not as large in size as in the ++ instance, the reading is considered + ; and where there is distinct agglutination, but between the masses a few unclumped bacteria, the reaction is called slight. Care is taken to examine the entire area to avoid the confusing clumping which usually occurs about the periphery of any drop of emulsion of bacteria.

As is seen from the foregoing, the readings are very conservative. In view of the short time (one hour) allowed for the reaction (in comparison with macroscopic tests, in glanders, for example, in which the readings are made at the end of 72-96 hours) we have a sufficient explanation for the average agglutination titer of $1: 200$ in typhus fever sera.

Furthermore, rabbit immune serum of high potency (demonstrated by the presence of precipitins and complement-fixing bodies in high dilutions) shows an agglutination titer varying between $1: 400$ and $1: 800$, when the tests are made in a similar manner. One would expect therefore that natural immune serum would give a lower titer, coinciding possibly with our findings of $1: 200$ in convalescent typhus fever cases.

Agglutination During the Course of Typhus Fever.-Here, as well as in our complement-fixation work, we dealt with two distinct strains of typhus bacilli at the inception of the work, the organism obtained from epidemic typhus fever and the one from endemic typhus fever. 
Comparative experiments demonstrated that an epidemic typhus agglutinogen gave clumping with serum from endemic typhus fe:er as well as from epidemic typhus fever, and that an endemic typhus agglutinogen likewise gave positive agglutination with serum from patients suffering from either form of typhus fever (Table 3 ).

TABLE 3

The Relation Between Endemic Typhus Agglutinogen and Epidenic Typhus Agglutinogen

\begin{tabular}{|c|c|c|c|c|c|c|c|c|c|c|}
\hline \multirow{2}{*}{ Case } & \multicolumn{5}{|c|}{ Endemle Typhus Agglutinogen } & \multicolumn{5}{|c|}{ Epidemic Typhus Agglntinogen } \\
\hline & $1: 20$ & $1: 50$ & $1: 100$ & $1: 200$ & $1: 400$ & $1: 20$ & $1: 50$ & $1: 100$ & $1: 200$ & $1: 400$ \\
\hline 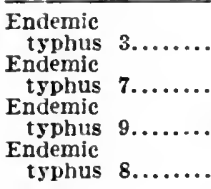 & $\begin{array}{c}+ \\
+ \\
\text { Slight } \\
++\end{array}$ & $\begin{array}{c}+ \\
+ \\
\text { Slight } \\
++\end{array}$ & $\left\{\begin{array}{c}+ \\
\text { Slight } \\
- \\
++\end{array}\right.$ & $\begin{array}{c}\text { Slight } \\
\text { Slight } \\
- \\
+\end{array}$ & $\begin{array}{l}- \\
- \\
- \\
-\end{array}$ & $\begin{array}{l}++ \\
- \\
+ \\
++\end{array}$ & $\begin{array}{l}++ \\
- \\
+ \\
++\end{array}$ & $\begin{array}{l}++ \\
- \\
- \\
-\end{array}$ & $\begin{array}{l}+ \\
- \\
- \\
-\end{array}$ & $\begin{array}{l}- \\
- \\
- \\
-\end{array}$ \\
\hline
\end{tabular}

These results are somewhat irregular. One would expect the typhus agglutinogen to react more powerfully in the three epidemic typhus cases than it did, but one should also consider that the strains used were freshly isolated while the endemic typhus strains were older. However, the cross agglutination between epidemic and endemic typhus fever is well illustrated.

In applying a mixed agglutinogen, i. e., one containing strains from both epidemic typhus fever and endemic typhus fever, positive agglutinations were obtained in more instances than positive complement fixations. In making up the tables, I have considered such reactions as occur in dilutions of $1: 50$ or higher as positive, for reasons which I shall give later.

Table 4 shows that in forty-three typhus cases (including the endemic form), during some period in the disease, thirty-nine, or 90.7 percent, were positive. Of these cases investigated, twenty-four were tested at the height of the disease. Here, all were negative but two, endemic typhus Cases 20 and 39, both having a titer of $1: 100$. In both cases, the blood was tested a day before the crisis occurred. Ten cases were tested on the day of the crisis; of these, seven were negative and three positive. In the apyrexial period, thirty-eight were studied; only three were negative, and 92.1 percent were positive. Hence we see, just as in our complement fixation work, that the agglutinins are 
usually absent at the height of the disease, but increase in amount at the crisis until they reach their maximum well along in the apyrexial period. In epidemic typhus Case 5, there was no agglutination four days after the crisis, but ten days later the serum agglutinated at $1: 50$. In endemic typhus Case 8 , while there was a negative reaction one day after, there was a positive reaction $(1: 200)$ six days after the crisis. Also in endemic typhus Case 15, a negative reaction two days after the crisis became $1: 200$ five days later.

TABLE 4

Agglutination During the Course of Typhus Fever

\begin{tabular}{|c|c|c|c|c|c|}
\hline \multicolumn{3}{|c|}{ Case } & $\begin{array}{l}\text { Height of } \\
\text { Disease }\end{array}$ & Crisis & $\begin{array}{l}\text { After Crisis } \\
\text { (Number of days precedes } \\
\text { result) }\end{array}$ \\
\hline Epidemic & typhus & $1 \ldots \ldots \ldots$ & - & Negative & \\
\hline & typhus & & Negative & - & $5,1: 100$ slight \\
\hline $\mathrm{mic}$ & typhus & 3.. & Negative & 一 & $3,1: 200+$ \\
\hline & typhus & $4 \ldots \ldots \ldots$ & Negative & - & $6,1: 100+$ \\
\hline emic & typhus & $5 \ldots \ldots \ldots$ & Negative & - & 4, negative; $14,1: 50+$ \\
\hline mic & typhus & $6 \ldots \ldots \ldots$ & - & - & $9,1: 100+$ \\
\hline $\operatorname{mic}$ & typhus & $7 \ldots$ & - & 一 & $3,1: 200+$ \\
\hline & typhus & 8. & - & - & $5,1: 100$ slight \\
\hline & typhus & $9 \ldots \ldots \ldots$ & - & 一 & $3,1: 100$ slight \\
\hline Epidemic & typhus & $10 \ldots \ldots \ldots$ & Negative & 一 & \\
\hline Epidemic & typhus & $11 \ldots \ldots$ & - & 一 & $4,1: 100+$ \\
\hline Endemic & typhus & $8 \ldots \ldots \ldots$ & Negative & - & 1, negative; $6,1: 200+$ \\
\hline $\begin{array}{l}\text { Endemic } \\
\text { Endemic }\end{array}$ & $\begin{array}{l}\text { typhus } \\
\text { typhus }\end{array}$ & $10 \ldots \ldots \cdots$ & Negative & Negative & \\
\hline End & typhus & $13 \ldots \ldots$ & - & Negative & $7,1: 200+$ \\
\hline & typhus & $14 .$. & Negative & & 5 , negative \\
\hline nic & typhus & $15 .$. & Negative & - & 2 , negative; $7,1: 200+$ \\
\hline & typhus & $16 .$. & - & - & $4,1: 200+; 7,1: 200+$ \\
\hline Eno & typhus & 17. & - & - & $4,1: 200+$ \\
\hline End & typhus & 18. & - & Negative & $4,1: 200+$ \\
\hline Endemic & typhus & 19. & $\overline{100}$ & $1: 350$ slight & \\
\hline Endemic & typhus & $20 \ldots$ & $1: 100+$ & - & $4,1: 100+$ \\
\hline $\begin{array}{l}\text { Endemic } \\
\text { Endemic }\end{array}$ & $\begin{array}{l}\text { typhus } \\
\text { typhus }\end{array}$ & $21 \ldots \ldots \ldots$ & $\begin{array}{l}\text { Negative } \\
\text { Negative }\end{array}$ & $1: 100+$ & $\begin{array}{r}5,1: 50{ }^{+} \\
30,1: 100{ }^{+}+: 64,1: 1200+\end{array}$ \\
\hline & & & Vontiva & & $113,1: 200$ slight; $154,1: 50+$ \\
\hline $\begin{array}{l}\text { Endemic } \\
\text { Endemic }\end{array}$ & $\begin{array}{l}\text { typhus } \\
\text { typhus }\end{array}$ & $23 \ldots \cdots \cdots$ & Negative & $=$ & $3,1: 200+: 7,1: 200+$ \\
\hline Ende & typhus & $25 \%$ & Negative & 二 & $\begin{array}{l}\frac{1}{1}, 1: 200+1 ; 1400+1: 200 \\
5,1: 14\end{array}$ \\
\hline End & typhus & 26. & Negat & - & $15,1: 800+$ \\
\hline & typhus & 27. & Negati & - & 5, negative \\
\hline nic & typhus & 28. & Negative & 一 & $1,1: 100$ slight \\
\hline & typhus & 29. & & - & $5,1: 500+$ \\
\hline Ende & typhus & 30. & Negati & - & $2,1: 100+; 9,1: 100+$ \\
\hline & typhus & & Negati & Negative & $3,1: 100+$ \\
\hline & typhus & 32. & Negative & $1: 800+$ & $3,1: 200+$ \\
\hline Ende & typhts & 33. & - & - & $7,1: 200$ slight \\
\hline Ende & typhus & $34 .$. & Negative ${ }^{\circ}$ & - & $6,1: 200+$ \\
\hline End & typhus & & - & NT & $150,1: 500+$ \\
\hline $\operatorname{mic}$ & typhus & $36 \ldots \ldots$ & - & Negative & 5, negative \\
\hline & typhus & $37 \ldots \ldots$ & Negative & Negative & 5, 1: 100 slight \\
\hline & $\begin{array}{l}\text { typhus } \\
\text { typhus }\end{array}$ & $38 \ldots \ldots$ & 100 & Negative & $\begin{array}{l}5,1: 100 \text { slight } \\
5,1: 100+\end{array}$ \\
\hline Endemic & typhus & $40 \ldots \ldots$ & Negative & & $6,1: 200$ slight \\
\hline
\end{tabular}

Daily agglutination tests (for some of which we are indebted to Dr. A. Brodey) performed on endemic typhus Case 15, showed that there were no agglutinations until four days after the crisis, when 
the titer was $1: 50$. The next day it rose to $1: 100$ and for seven days in the apyrexial stage was 1:200, the level at which it remained. Likewise in endemic typhus Case 17, daily tests showed that no agglutinins were present until the fourth day after crisis, when the titer reached $1: 200$. We may conclude then that the maximal concentration of agglutinins appears about four days after the crisis.

In regard to the persistence of agglutinins, we may state that they are demonstrable at least five months after the crisis. Endemic typhus Case $35^{*}$ showed a reaction of $1: 500$ five months after the crisis. Endemic typhus Case 22, during varying periods after the crisis, showed the following reactions:

Days after Crisis
30
64
113
154

$$
\begin{gathered}
\text { Reaction } \\
1: 1000 \\
1: 1200 \\
1: 200 \\
1: 50
\end{gathered}
$$

In this case there was a positive complement fixation $(++++)$ on the sixty-fourth day, but a negative reaction thereafter. It is probable, then, that complement-fixing bodies disappear much more quickly than the agglutinins.

Agglutination Tests on Control Cases.-A great many of the control cases were tested both for complement fixation and agglutination. There were forty-four cases in this series, and the diagnosis included a great variety of conditions. In seven of these cases, there occurred agglutination in a dilution of $1: 20$, but none in higher dilutions. Of the seven cases, one was a brain tumor; two, valvular defects; two, general paresis; one, carcinoma of the tonsil; and one a case of alcoholism. In all, complement fixation was negative. It is on this account that in the tabulations I regarded only such results positive as gave agglutination in dilutions of 1:50 or higher.

These non-specific reactions in low dilutions are not peculiar to typhus fever. It is now generally accepted that traces of antibodies may be found in normal serum, but in immune serum these are increased to greater or less degrees. Or, in the foregoing instance, when the dilutions are so low, "serum action" (probably through a colloid phenomenon) is the cause of the clumping.

- This patient was in a debilitated condition for five months after an attack of supposed typhoid fever, lasting ten days, accompanied by severe headache. As it did not seem likely that an attack of typhoid fever of such short duration would so weaken an individual, the possibility of typhus fever was entertained by Dr. Libman, who referred the case to us for serologic study. 
Besides those mentioned, there was another series of twelve cases. These were sent to us for diagnosis, and subsequent investigation proved that none of the cases was typhus fever. All these showed negative agglutination reactions. All cases were febrile and included such conditions as typhoid fever, meningitis, tuberculosis, influenza, etc. In these the blood was tested both during the febrile stage and in the post-critical period, with the same negative results.

A third series of controls comprised forty cases. Of these, three cases gave positive results. Case 1 was an adult male who was suffering from cellulitis of the hand at the time the test was made. He gave a history of having served in an army corps stationed at the Mexican border some years ago, and at that time he had been seized with a severe illness, for which he had been treated at the camp hospital. Because of his incipient paresis, he was unable to give a detailed account of his illness. The other two cases were immigrants living in the slums. Because of their lack of intelligence, a proper previous history could not be obtained. The first case showed agglutination of $1: 100$; the other two, $1: 200$. Complement-fixation tests in all three were negative. It is reasonable to suppose that these three cases (from a total of ninety-six controls tested) had had, at one time or another, typhus fever.

Agglutination With Other Than Typhus Organisms.-During the course of this work, I have endeavored to use as agglutinogens all such bacteria as we were able to obtain, in cases other than typhus fever, that had in any way some resemblance morphologically to the typhus bacillus. In all such instances, when the agglutinogen was mixed with convalescent typhus serum, the results were negative. For instance, in the case of Bacillus acnes (for several strains of which we are indebted to Dr. E. P. Bernstein, Lebanon Hospital, and to Dr. C. E. A. Winslow, Museum of Natural History, New York City), one of our reports shows:

\begin{tabular}{c|c|c}
\hline \hline \multirow{2}{*}{ Dilutions of Immune Serum } & \multicolumn{2}{|c}{ Agglutinogen } \\
\cline { 2 - 3 } & Bacillus Acnes & Bacillus Typhi-Exanthematici \\
\hline $1: 20$ & Negative & ++ \\
$1: 50$ & Negative & + \pm \\
$1: 100$ & Negative & ++ \\
$1: 200$ & Negative & + \\
$1: 400$ & Negative & +50 \\
$1: 500$ & Negative & + \\
1 & & + \\
\hline
\end{tabular}




\section{PRECIPITIN IN TYPHUS FEVER}

We have demonstrated that in serum from typhus fever convalescents there are present specific precipitins which react with filtrates of the typhus bacilli. Our attention was first called to the fact that precipitins may be present by the appearance of a precipitate in immune rabbit serum which was kept in the cold. This rabbit had had injected large doses of bacteria and the blood, when withdrawn, contained possibly precipitogen and precipitin at the same time.

\section{METhods}

The precipitogen was prepared by inoculating 2 percent glucose broth with typhus bacilli and allowing cultures to grow one month. Different strains were used so as to give a polyvalent precipitogen. The cultures were inserted into Buchner tubes or Noguchi tubes, and the media, in such cases, covered over with sterile liquid petrolatum. No serum was used in these cultures. The sediment or growth of each tube having been stained to be certain of its purity, the entire material was then filtered through a Berkefeld filter. The clear filtrate was employed as precipitogen. We have tried the method of Besredka of precipitating the protein of the bacterial cells, drying, and subsequently suspending the residuum in saline or water, but the former method is more advantageous. The serum used was cleared and inactivated. Dilutions were made at the beginning of the work of $1: 100,1: 500,1: 1000,1: 1500$, and 1:5000. Control tests consisted in using an immune (rabbit) serum of known titer and a known negative serum (from a case not having typhus fever). The test was performed by adding 1 c.c. of precipitogen to 0.5 c.c. of each dilution in individual test tubes. The results were read at the end of two hours at $37 \mathrm{C}$. When no reaction was noticed at the end of this time, such tests were placed in the ice box over night. Care must be exercised in reading reactions in over night tests, for precipitations may occur which are due to contaminations, usually with Bacillus subtilis. Subcultures should be made to eliminate such errors. However, most of our tests were read at the end of two hours at $37 \mathrm{C}$. Some showed clouding in low dilutions almost immediately on the addition of the precipitogen.

After we had obtained several positive results, we simplified the method and employed only six tubes. Tube 1 contained 0.05 c.c. of suspected serum; Tube 2 contained 0.01 c.c. of suspected serum; Tube 3 contained 0.5 c.c. of suspected serum; Tube 4 contained 1.0 c.c. of suspected serum; Tube 5 contained 0.05 c.c. of immune serum; Tube 6 contained 1.0 c.c. of control (negative) serum. In all tubes, 2 c.c. precipitogen were added and sufficient saline to equalize to 3 c.c. Readings were made at the end of two hours at $37 \mathrm{C}$.

Precipitin During the Course of Typhus Fever.-There is considerable resemblance in the results obtained in investigating precipitin to those obtained in the study of agglutinin and complementfixing antibodies. 
Of ten cases studied at the height of the disease, all were negative. Three cases were tested in which the blood was withdrawn at the crisis. Of these one showed distinct clouding in 1:1000 dilution. Of the nineteen cases tested in the apyrexial period, fourteen, or 73.6 percent, gave precipitations. Three of these reacted in dilutions of $1: 1500$; four in dilutions of $1: 1000$, while the rest showed precipitates in dilutions of $1: 100$ (Table 5).

TABLE 5

Precipitin During the Course of Typhus Fever

\begin{tabular}{|c|c|c|c|c|c|}
\hline - & Case & & $\begin{array}{l}\text { Height of } \\
\text { Disease }\end{array}$ & Crisis & $\begin{array}{c}\text { After Crisis } \\
\text { (Days after crisis precedes } \\
\text { results) }\end{array}$ \\
\hline $\begin{array}{l}\text { Epidemic } \\
\text { Endemic } \\
\text { Endemic } \\
\text { Endemic } \\
\text { Endemic } \\
\text { Endemic } \\
\text { Endemic } \\
\text { Endemic } \\
\text { Endemic } \\
\text { Endemic } \\
\text { Endemic } \\
\text { Endemic } \\
\text { Endemic } \\
\text { Endemic } \\
\text { Endemic } \\
\text { Endemic } \\
\text { Endemic } \\
\text { Endemic } \\
\text { Endemic } \\
\text { Endemic } \\
\text { Endemic } \\
\text { Endemic } \\
\text { Endemic } \\
\text { Endemic }\end{array}$ & $\begin{array}{l}\text { typhus } \\
\text { typhus } \\
\text { typhus } \\
\text { typhus } \\
\text { typhus } \\
\text { typhus } \\
\text { typhus } \\
\text { typhus } \\
\text { typhus } \\
\text { typhus } \\
\text { typhus } \\
\text { typhus } \\
\text { typhus } \\
\text { typhus } \\
\text { typhus } \\
\text { typhus } \\
\text { typhus } \\
\text { typhus } \\
\text { typhus } \\
\text { typhus } \\
\text { typhus } \\
\text { typhus } \\
\text { typhus } \\
\text { typhus }\end{array}$ & 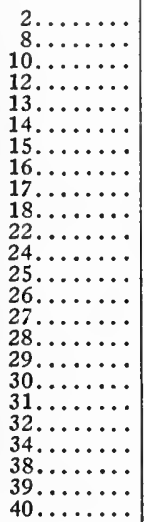 & 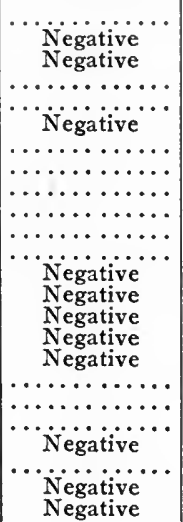 & 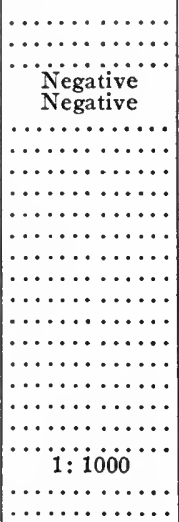 & $\begin{array}{l}\text { 5, } 1: 100 \\
6,1: 100 \\
7,1: 100 \\
7,1: 100 \\
7, \text { negative } \\
7,1: 1000 \\
\text { 4, } 1: 100 \\
\text { 30, } 1: 1500 \\
\text { 1, negative; } 7,1: 1500 \\
\text { 15, 1: 1000 } \\
\text { 5, 1: } 1500 \\
\text { 5, negative } \\
\text { 2, negative; } 9, \text { negative } \\
\text { 3, negative } \\
\text { 3, 1: 1000 } \\
6, \text { negative } \\
\text { 5, } 1: 100 \\
6,1: 100\end{array}$ \\
\hline
\end{tabular}

Table 5 shows that precipitin is absent at the height of the disease but becomes in evidence at the crisis. Thence it proceeds to increase until well along in the post critical stage (see endemic typhus Case 24: one day after crisis, no precipitation; seven days after, positive $1: 1500)$.

With each test, as was stated, a negative serum was included. Of numerous such control cases, none has shown a positive reaction. This is in accord with our knowledge of precipitins, since these bodies are regarded as highly specific.

\section{OTHER ANTIBODIES IN TYPHUS FEVER}

Bacteriolysins (Bacteriocidins).-We could not determine in typhus fever immune serum the presence of bacteriolysins or bacteriocidins against the typhus bacillus. This does not signify that no such anti- 
bodies exist, but that, if present, we have not as yet been able to devise a method for their detection. The reasons for this are:

(1) Animal experimentation is unsuitable. The organism rapidly loses its virulence, hence the protective power of immune serum can not be studied, since the control animals (those injected with bacteria alone) are not affected.

(2) In vitro, bacteriolysin experiments are equally without result. We have tried the plate method, using serial dilutions of immune serum (to obviate the complement deviation of Neisser-Wechsberg), as well as a capillary pipette method, but in all experiments the control plate (i. e., plate poured from a mixture of organisms and saline alone) would show no growth, or, at the utmost, one or two colonies. We could not maintain in our plate experiments the strict anaerobiosis that the organism requires.

TABLE 6

The Opsonic Variations in Endemic Typhus, Case 17

\begin{tabular}{|c|c|c|c|}
\hline \multirow{2}{*}{ Day of Disease } & \multicolumn{2}{|c|}{$\begin{array}{c}\text { Average Number of Bacteria Taken } \\
\text { up by Phagocytes in }\end{array}$} & \multirow{2}{*}{ Index } \\
\hline & $\begin{array}{l}\text { Pooled Normal } \\
\text { Sera }\end{array}$ & $\begin{array}{l}\text { Typhus } \\
\text { Serum }\end{array}$ & \\
\hline 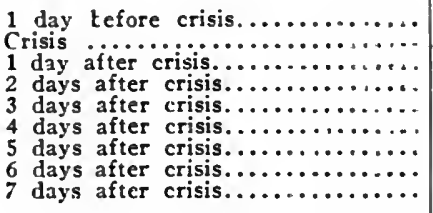 & $\begin{array}{l}2.0 \\
3.2 \\
5.0 \\
5.4 \\
2.9 \\
1.5 \\
2.5 \\
1.7 \\
1.2\end{array}$ & $\begin{array}{l}1.8 \\
3.2 \\
5.5 \\
7.0 \\
4.2 \\
2.2 \\
3.2 \\
2.2 \\
2.4\end{array}$ & $\begin{array}{l}0.9 \\
1.0 \\
1.1 \\
1.4 \\
1.49 \\
1.5 \\
1.47 \\
1.3 \\
2.0\end{array}$ \\
\hline
\end{tabular}

(3) We have attempted to reproduce Pfeiffer's phenomenon in guinea-pigs, using typhus immune pigs and typhus bacilli, but there was no bacteriolysis as in cholera. In this respect, if there are no bacteriolysins present, typhus fever would form no exception, since it is well known that the organisms of the hemorrhagic septicemia group, altho their immune sera contain complement-fixing bodies, yet show no bacteriolysins. Numerous experiments were made in which bacteria were suspended in serial dilutions of immune serum, but here, as well, no lysis of the typhus bacilli was noted. In all instances the organisms became gram-negative, but the same change was noted with normal serum controls. However, we do not wish to state definitely, on the basis of this series of experiments, that there are bacteriolysins present 
in typhus immune serum unless we can substantiate the results with animal investigations, using a virulent strain of the organism.

Opsonins.-That immune opsonins against this organism are present in typhus immune serum is quite evident. In testing for opsonins, Wright's method was used with inactivated serum.

While discrepancies are common with this method (and such have occurred here, when two workers repeated the same test), yet the average results demonstrate that the opsonic index increases at the crisis and remains high in the convalescent stage of the disease. An example of this will be seen by reference to Table 6, endemic typhus Case 17. In this case, all tests were made by the same individual.

Similar rises were noted in artificially immunized serum (rabbit). The probability is that this method is one of the most potent, on the part of the patient, in overcoming the infection. We noted, during these examinations, that bacteria taken up by phagocytes had a marked tendency to become fragmented and take the stain very lightly. Lysis of the typhus bacilli apparently is very active within polymorphonuclear cells of typhus immune subjects.

Other features of this work, the occurrence of allergic reactions (using extracts of typhus bacilli as allergens) and the nature of the toxin produced, which are in progress now, will be reported later.

Having thus demonstrated the presence of various antibodies in typhus fever serum, I shall now discuss certain phenomena depending upon these facts.

THE IDENTITY OF THE ORGANISM ISOLATED FROM CASES OF ENDEMIC TYPHUS FEVER WITH THAT ISOLATED FROM CASES OF EPIDEMIC TYPHUS FEVER

It was my first endeavor to ascertain the serologic relation of the endemic strain of the typhus bacillus to that isolated from epidemic typhus fever. This was studied by cross fixation, both in artificially produced immune serum and in natural immune serum, and similarly by cross agglutination.

Artificially produced immune serum was prepared by the method previously described. Rabbits were immunized both to epidemic typhus fever strains and to an endemic strain, for at that time there were available five strains of epidemic typhus fever organisms (A, $S, 1,3,4$ ) and but one from endemic typhus (B 40). Individual 
antigens were likewise prepared, one containing none but epidemic typhus strains, the other, the endemic strain.

Table 7 presents the results of experiments in cross fixation. From this it will be seen that the bacteria isolated from epidemic typhus fever and those from endemic typhus fever are merely two strains of the same organism.

\section{TABLE 7}

Experiments in Cross Fixation witil Rabbit Imaune Serum

(a) Titrations with Epidemic Typhus Strains Antigen

$\begin{array}{llllllll}\text { Amount of serum.................. } & 0.0005 & 0.001 & 0.005 & 0.01 & 0.05 & 0.1 \\ \text { Epidemic lyphis immune seruin..... } & + & + & + & + & + & + \\ \text { Endemic typhus immune serum...... } & 0 & \pm & + & + & + & +\end{array}$

(b) Titration with Endemic Typhus Strain Antigen

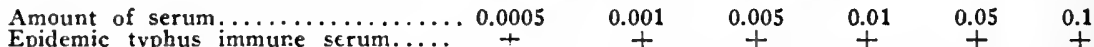
Endemic typhus immune serum...... $\frac{t}{0}+ \pm+t+$ The sign $+=$ inhibition of hemolysis; $\pm=$ incomplete inhibition of hemolysis; $0=$ hemolysis.

TABLE 8

Experiments in Cross Agglutination with Immune Rabit Serum

(a) Using Endemic Typhus Strain Immune Serum

\begin{tabular}{c|c|c}
\hline \hline Serum Dilution & $\begin{array}{c}\text { Epidemic Typhus Strains } \\
\text { Agglutinogen }\end{array}$ & $\begin{array}{c}\text { Endemic Typhus Strain } \\
\text { Agglutinogen }\end{array}$ \\
\hline $1: 20$ & + & ++ \\
$1: 50$ & + & + \pm+ \\
$1: 100$ & + & + \\
$1: 400$ & $\begin{array}{c}\text { Slight } \\
\text { Negative } \\
\text { Negative }\end{array}$ & + \\
$1: 600$ & Slight
\end{tabular}

(b) Using Epidemic Typhus Strains Immune Serum

\begin{tabular}{l|c|c}
$1: 20$ & ++ & ++ \\
$1: 50$ & + \\
$1: 100$ & + & + \\
$1: 200$ & Negative & $\begin{array}{c}+ \\
\text { Slight } \\
\text { Negative }\end{array}$ \\
\hline
\end{tabular}

In the case of natural immune serum, as we have it in convalescent epidemic typhus fever patients, the same phenomenon is to be noted. A comparison with Table 1 will show that endemic typhus immune serum has the same specific complement-fixing bodies as epidemic typhus fever immune serum.

Agglutination proves the same point, namely, that the specific agglutinin developed in epidemic typhus immune serum is the same as that in endemic immune serum. This could be demonstrated in artificially produced immune serum as well as in natural (Tables 3 and 8 ). In the artificially produced immune serum, the agglutinogen 
that corresponds to the strain used in immunization gives a higher titer, which is to be expected.

We therefore conclude that from a serologic viewpoint, both these types, the organism obtained from endemic and the one from epidemic typhus fever, are two strains of the same bacterium.

\section{SEROLOGIC STUDIES IN ANIMALS}

Monkeys.-It was the practice to test the serum of monkeys, before use, for complement-fixing bodies, as well as agglutinins. In this way, not only could the subsequent reactions be studied more accurately, but we also learned that the average normal monkey has no such antibodies present. In the experiments with eight normal monkeys, complement fixation, as well as agglutination, was negative.

Experimental typhus fever in the monkey gave rise to serologic changes in the same manner as in human beings, as will be seen by consulting Table 9. Hence, of six monkeys that reacted to the typhus virus, complement-fixation and agglutination tests were positive in five, or 83.3 percent. These reactions were still positive twenty days after the crisis.

TABLE 9

Complement Fixation and Agglutination in Monkeys

\begin{tabular}{|c|c|c|c|c|c|}
\hline $\begin{array}{l}\text { Number of } \\
\text { Monkey }\end{array}$ & $\begin{array}{l}\text { Date of } \\
\text { Injection } \\
\text { of Virus }\end{array}$ & $\begin{array}{l}\text { Duration of } \\
\text { Reaction }\end{array}$ & $\begin{array}{c}\text { Complement } \\
\text { Fixation }\end{array}$ & Agglutination & $\begin{array}{c}\text { Number of } \\
\text { Days After } \\
\text { Crisis Tested }\end{array}$ \\
\hline $\begin{array}{r}1 \\
2 \\
3 \\
7 \\
10 \\
11\end{array}$ & $\begin{array}{lr}\text { Jan. } & 7 \\
\text { Jan. } 29 \\
\text { Jan. } 21 \\
\text { Feb. } & 5 \\
\text { Jan. } 21 \\
\text { Jan. } 29\end{array}$ & $\begin{array}{c}\text { Jan. } 7-20 \\
\text { Feb. } 5-12 \\
\text { Jan. 29-Feb. } 5 \\
\text { Feb. 13-21 } \\
\text { Feb. } 5-13 \\
\text { Feb. } 5-11\end{array}$ & $\begin{array}{c}++++ \\
++ \\
\text { Negative } \\
++ \\
++ \\
++\end{array}$ & $\begin{array}{c}1: 200 \\
1: 100 \text { (slight) } \\
\text { Negative } \\
1: 100 \\
1: 100 \text { (slight) } \\
1: 100\end{array}$ & $\begin{array}{r}8 \\
20 \\
27 \\
8 \\
11 \\
13\end{array}$ \\
\hline
\end{tabular}

The effect of repeated injections of monkeys with avirulent, living, non-sensitized typhus bacilli, was investigated. In animals in which previous reactions were negative, large doses were required before there was any noticeable change in the serum content of antibodies.

Monkey 2 was injected with living, avirulent vaccine of typhus bacilli on October 8, 12, and 17, in doses of two billion, four billion, and four billion, respectively. October 18 , its blood showed a ++ complement fixation, but a negative agglutination. Of course, in this instance, there was a short interval between the last injection and the withdrawal of the blood. However, this vaccination was continued for three additional injections with dosages running up to eight billion. Five days after the last injection, the complement-fixation test showed ++++ , and the agglutination titer was $1: 500$. 
Monkey 1 likewise received six injections. Nine days after the last injection, blood was withdrawn and tested. Complement fixation showed ++++ and the agglutination titer was $1: 100$.

Monkey 3 showed the same results with five injections, dosages varying from four to six billion.

Monkey 6 after six injections of from three to ten billion dosage showed, nine days after the last injection, a complement fixation of ++++ and an agglutination of $1: 500$.

However, in such "vaccinated" animals, these reactions may disappear after a time.

Monkey 2, on November 3, 1914, showed a ++++ complement fixation and 1:500 agglutination. On January 3, 1915 (two months later), the reactions were negative. Monkey 3 , on the former date, gave a ++++ complement fixation and 1:100 agglutination. Two months later these likewise disappeared. Monkeys 1 and 6 retained their reactions, altho somewhat weaker in degree, during this time.

As the agglutination in typhoid fever is no absolute sign of protection from that disease, so in typhus fever, complement fixation and agglutination, while often appearing in immunity, are no indications of immunity. The four monkeys mentioned, two with reactions and two without, were injected with active typhus virus. Three monkeys $(1,2$, and 3 ) did, while one did not, react (6). Of the three showing typical typhus fever, one had given complement fixation and agglutination previously to being inoculated with the virus (Monkey 1), while two had been without such manifestation (Monkeys 2 and 3 ). Hence, in spite of the presence of complement-fixing bodies and agglutinins, experimental typhus fever could be produced. In two of these monkeys, the reactions reappeared after the crisis had occurred.

The production of complement-fixing bodies as well as agglutinins in monkeys can be paralleled in man. In regard to the latter, in one case, four injections were given, at intervals of five days, of 100, 250, 500 , and 1,000 million killed, non-sensitized bacteria. Nine days after the last injection, the reactions were negative. In another case (Dr. H. Plotz, Dr. A. Loewenthal, and Dr. A. Brodey volunteering their services to act as subjects for vaccination), five injections were given subcutaneously at five-day intervals, of $250,500,1,000,1,500$, and 2,000 million killed, non-sensitized bacteria. Nine days after the last injection, the complement fixation was ++++ , while the agglutination titer was $1: 500$.

The results in prophylactic vaccination against typhus fever, a work which is now in progress, will be reported later. 
Guinea-Pigs.-The results of the serologic investigations in typhusimmune guinea-pigs were quite different from those in other animals.

Guinea-pig 4 was injected with blood from typhus Case 3 on April 14, 1914, and reacted April 22. On June 16, it was again injected with a guinea-pig typhus virus. There was no reaction, hence the animal was proved immune. This animal was bled July 6 , and the serum was then studied. Normal guinea-pig serum was used for control.

Altho the animal was proved immune, yet the serum contained no agglutinin or complement-fixing bodies. The same results were obtained on repetition of this experiment. It is most probable that the guinea-pig reacts to the typhus virus and develops subsequently a high grade of immunity by means of its tissue elements and only to a very slight degree by means of the circulating blood. In this respect, there is the analogous tolerance of rats to diphtheria toxin, altho no circulating antitoxin is demonstrable.

There is another possibility in that the opsonins may exert great influence in these animals and likewise add to the factors of the cellular immunity which may be present. When guinea-pig leukocytes and inactivated immune serum were used, the latter gave much higher indices than normal, inactivated guinea-pig serum.

Rabbits.-Rabbits are not susceptible to the typhus bacillus in small amounts. If given intravenously in large doses, they will succumb in 3-7 days. In such animals, the autopsy reveals no distinct pathologic changes. The animals do not develop a carrier state, as they do in the case of typhoid bacilli, but die most likely from toxemia.

When small yet increasing amounts of bacteria are given, rabbits develop very potent immune serum. I shall illustrate the serum studies on the rabbit by giving a report of one of the typically reacting rabbits.

Rabbit B was injected on May 26, 30, June 3, and 7, 1914, with one-half the growth on a slant, the full growth on one, two, and three slants, respectively. The first two injections were with killed bacteria, the second two with live organisms. Since the growth on a slant is not very luxuriant, these quantities represent fewer organisms than one might presuppose. As many different strains as possible were used to prepare immune serum. Nine days after the last injection, June 16, 1914, the rabbit was bled from the internal jugular vein and in that manner serum obtained. The serum in this instance showed: Complement fixation ++++ with 0.0005 c.c. serum; agglutination $1: 500+$; precipitation $1: 2500+$; opsonic index (compared with non-immunized rabbits) 3.0. Unfortunately, the bactericidal experiments were impossible for the reasons stated. This immune serum, however, produces no lysis of the bacteria when the former is added to the latter in vitro. 
When such immune serum was titrated against different strains as antigens, it was found that all strains cross-fixed to a greater or less degree, but that there were appreciable differences between epidemic typhus and endemic typhus strains. In other words, the typhus bacillus is divided into two distinct strains: the epidemic typhus and the endemic typhus strains.

\section{SEROLOGIC REACTIONS IN INDIVIDUALS AFTER EXPOSURE TO TYPHUS FEVER}

Observations made upon the serum of two individuals proved very interesting. In both, there was a definite exposure to the typhus virus: one (Dr. B.) to the endemic and epidemic types; the other (Miss L.) to the epidemic form only. At no time did either of them have any symptoms which were recognizable as due to typhus fever. Yet they showed complement-fixing antibodies and agglutinins in this manner:

\begin{tabular}{c|c|c}
\hline \hline Date & Complement Fixation Test & Agglutination Test \\
\hline & Dr. B. & \\
Dec. 15, 1914 & ++++ & $1: 500+$ \\
Dec. 21, 1914 & +++ & $1: 200+50+$ \\
Aarch 1, 1915 & Negative & $1: 20+$ \\
& Miss L. & \\
April 17, 1915 & ++++ & $1: 200+$ \\
\hline
\end{tabular}

The significance of these reactions will be discussed in the following section on experimental studies in typhus fever.

\section{THE RELATION BETWEEN THE SEROLOGIC RESULTS AND TYPHUS}

FEVER. CONCLUSIONS

There is a most intimate relation between the typhus bacillus and typhus fever. The serologic reactions occur in an orderly manner. Complement-fixing bodies are usually not seen at the height of the disease, but are demonstrable as the crisis is attained and increase in concentration in the post critical, afebrile state; the same is true of agglutinins, as well as precipitins. These antibodies are developed in the body as the result of an antigen circulating at the height of the disease. They are demonstrated in vitro when the organism isolated from the blood of typhus fever patients is used as artificial antigen. Hence, but one conclusion is possible, typhus fever is a reaction against this organism. 
Altho these reactions occur in coincidence with the process of immunity, they are merely signs which usially appear in immunization, but are not indicators of the existence of absolute immunity.

In so far as these reactions relate to the results of the blood cultures in typhus fever, these facts were noted:

There were sixteen cases in which the blood culture was taken at the height of the disease and in which bacteria were not found. In Table 10, it will be seen that most of our strongest serologic reactions occurred in just such cases.

TABLE 10

The Relation Between Negative Blood Cultures and Serologic Reactions

\begin{tabular}{|c|c|c|c|c|}
\hline Case & $\begin{array}{c}\text { Result of } \\
\text { Blood } \\
\text { Culture }\end{array}$ & $\begin{array}{c}\text { Complement } \\
\text { Fixation }\end{array}$ & $\underset{\text { tion }}{\text { Agglutina- }}$ & $\begin{array}{c}\text { Precipita- } \\
\text { tion }\end{array}$ \\
\hline 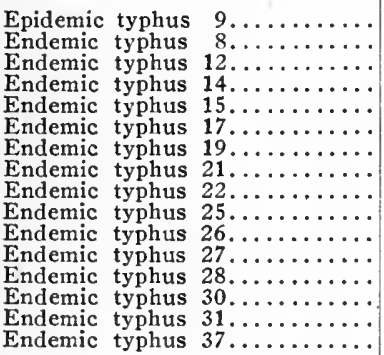 & $\begin{array}{l}\text { Negative } \\
\text { Negative } \\
\text { Negative } \\
\text { Negative } \\
\text { Negative } \\
\text { Negative } \\
\text { Negative } \\
\text { Negative } \\
\text { Negative } \\
\text { Negative } \\
\text { Negative } \\
\text { Negative } \\
\text { Negative } \\
\text { Negative } \\
\text { Negative } \\
\text { Negative }\end{array}$ & $\begin{array}{c}++ \\
++t \\
\text { Negative } \\
\text { Negative } \\
++ \\
++++ \\
+++\end{array}$ & $\begin{array}{l}1: 100 \\
\text { Negative } \\
\text { Negative } \\
\text { Negative } \\
1: 200 \\
1: 200 \\
1: 350 \\
1: 50 \\
1: 1200 \\
1: 1400 \\
1: 800 \\
\text { Negative } \\
1: 100 \\
1: 100 \\
1: 100 \\
1: 100\end{array}$ & $\begin{array}{l}\text { Not done } \\
\text { Positive } \\
\text { Negative } \\
\text { Not done } \\
\text { Positive } \\
\text { Positive } \\
\text { Not done } \\
\text { Not done } \\
\text { Positive } \\
\text { Not done } \\
\text { Positive } \\
\text { Positive } \\
\text { Negative } \\
\text { Negative } \\
\text { Negative } \\
\text { Not done }\end{array}$ \\
\hline
\end{tabular}

There are two exceptions in the endemic typhus Cases 12 and 14. In both these, not only the blood culture, but all the serologic reactions are negative. Here the suspicion arises as to whether they were really cases of endemic typhus fever. However, they were included in our records as the clinical picture resembled endemic typhus fever.

In cases in which the blood cultures were positive (twenty cases), there were only four instances where the complement fixation showed ++++ , and in no case was the agglutination titer higher than $1: 200$. There is apparently no relation in the degree of the serologic reactions to the number of colonies isolated in positive blood cultures.

The presence of these antibodies to the typhus bacillus having been shown, and also their manner of production and their relation to typhus fever, as well as their absence in cases other than epidemic or endemic typhus fever, the connection between this organism and typhus fever becomes apparent. 


\section{EXPERIMENTAL STUDIES*}

George Baehr, Harry Plotz, and Peter K. Olitsky

In this section, we shall confine ourselves to a report of that part of the experimental work on typhus fever which has a bearing upon the etiology of the disease. The work upon the artificial production of immunity is still in progress, and except for those observations which possess some etiologic significance, its presentation will be reserved for a future communication.

The results of the investigation which forms the basis of this report have supplemented the findings of the bacteriologic and serologic investigations, and have supplied additional methods of proof that the organism discovered by Dr. Plotz ${ }^{105}$ in 1914 is the etiologic agent in typhus exanthematicus.

The experiments were chiefly carried out upon monkeys and guinea-pigs, 13 macacus rhesus monkeys and about 350 guinea-pigs being used. (The active assistance of Dr. A. Brodey and Dr. H. Zamkin during the course of the work was of great value and is much appreciated.) For the purpose of propagating the various strains of typhus virus-a term used throughout this paper to designate infectious blood of an individual or an animal with typhus fever in contradistinction to the bacillus itself-and for much of the experimental work, guinea-pigs proved as satisfactory as monkeys, an experience which coincided with that of Anderson and Goldberger ${ }^{2}$ and other workers ${ }^{02}$.

For part of the work, eight strains of typhus virus were used. Six were obtained through the kindness of Dr. J. J. O'Connell from individuals with epidemic typhus fever who entered the port of New York after the Balkan Wars, and two from patients in the wards of the Mount Sinai Hospital who were suffering from the local endemic typhus known generally in the United States as Brill's disease ${ }^{24},{ }^{25}$. One. of the latter strains was sent to us by Dr. Anderson, who had originally obtained it from a case in the wards of the Mount Sinai Hospital on September 20,1911, ${ }^{6}$ and had kept it alive since that time by repeated passages through monkeys and guinea-pigs. We were readily able to confirm his observation ${ }^{2}$ that during that time it had undergone no apparent change in its virulence, the disease produced in animals by its inoculation being indistinguishable from that which

"This work was done under the tenure of the Eugene Meyer, Jr., and Moses Heineman Fellowships in Pathology. 
followed the inoculation of any other typhus virus after its first passage through a guinea-pig.

Before entering into the details of the experimental work, a brief survey of the most important results of previous investigations in this field is advisable.

That the virus of typhus fever is present in the circulating blood during the febrile period of the disease was discovered by Moczutkowski, ${ }^{\text {s1 }}$ who in 1876 inoculated himself with the blood of a typhus patient and eighteen days later developed the disease. Nicolle ${ }^{\mathrm{n} 0}$ first succeeded in inoculating a chimpanzee with the disease, and subsequently was able to transfer the infection from the chimpanzee to the macacus sinicus monkey. The macacus rhesus monkey was first proved to be susceptible to the direct inoculation of human virus by Anderson and Goldberger. ${ }^{10}$ And the susceptibility of the guinea-pig to the disease was discovered by Ricketts and Wilder. ${ }^{117}$

These workers found that inoculation of an animal with an active typhus virus is succeeded by an incubation period usually of seven to fourteen days' duration, occasionally somewhat longer, after which the animal runs a febrile course, usually lasting from four to eleven days. During this time the temperature ranges between 104 and $106 \mathrm{~F}$. (40 and 41 C.) and the blood is usually infective for other animals.

After the defervescence of the ${ }^{E}$ fever by crisis, or rapid lysis, the animals were found to possess an immunity to the disease, which, in one monkey tested by Anderson, ${ }^{2}$ lasted at least two and a half years. Anderson and Goldberger ${ }^{10}$ likewise demonstrated that animals which have recovered from the Mexican typhus fever are also immune to the virus of Brill's disease, and vice versa, thereby indicating the relationship, tho not the identity, of the two diseases.

That the louse can act as the intermediary host in the transfer of typhus virus from man to monkey and from monkey to monkey has been proved independently by the experiments of Nicolle, Compte, and Conseil, ${ }^{0+4}$ Ricketts and Wilder, ${ }^{118}$ and Anderson and Goldberger. ${ }^{18}$ And recently, Sergent, Foley, and Vialatte $^{123}$ have used lice to effect a transfer of virus from man to man.

8 These are the main facts which have been determined up to date by experimental research. The first point for us to ascertain was whether the organism recovered from the blood of typhus fever patients was also found in animals in which the disease had been produced by the inoculation of typhus blood.

\section{BLOOD CULTURES ON ANIMALS WITH TYPHUS FEVER}

For this purpose a series of twenty-four guinea-pigs was inoculated with 2.5-4 c.c. of defibrinated blood obtained from patients or animals with typhus fever and diluted with an equal volume of normal salt solution. The blood cultures were then made sometime after the onset of the fever in the following manner: 
The hair over the ventral aspect of the thorax was epilated with a concentrated solution of sodium sulfid and the denuded area disinfected with alcohol followed by tincture of iodin. With a needle and syringe, the chest wall was then punctured in the third or fourth intercostal space to the left of the sternum and blood aspirated directly from the heart. This was cultured in deep tubes of 2 percent glucose ascitic fluid agar in the manner previously describeci.

Table 1 shows the result of the blood cultures made upon this series of twenty-four guinea-pigs.

TABLE 1

Blood Culture Studies upon Animals

\begin{tabular}{|c|c|c|c|c|c|}
\hline $\begin{array}{l}\text { Number of } \\
\text { Guinea-pig }\end{array}$ & $\begin{array}{c}\text { Severity of } \\
\text { Febrile } \\
\text { Reaction }\end{array}$ & $\begin{array}{l}\text { Day of } \\
\text { Disease }\end{array}$ & $\begin{array}{c}\text { Temperature } \\
\text { When Culture } \\
\text { Was Made } \\
\text { F. }\end{array}$ & $\begin{array}{c}\text { Quantity of } \\
\text { Blood } \\
\text { Cultured } \\
\text { c.c. }\end{array}$ & $\begin{array}{c}\text { Result } \\
\text { in } \\
\text { Colonies }\end{array}$ \\
\hline $\begin{array}{l}12 \\
13 \\
16 * \\
21 \\
24 \\
27 \\
28 \\
38 \\
44 \\
46 \\
55 \\
56 \\
58 \\
63 \\
65 \\
69 \\
74 \\
75 \\
76 \\
85 \\
87 \\
102 \\
103 \\
105\end{array}$ & $\begin{array}{c}\text { Mild } \\
\text { Mild } \\
\text { Mild } \\
\text { Severe } \\
\text { Severe } \\
\text { Severe } \\
\text { Severe } \\
\text { Mild } \\
\text { Mild } \\
\text { Mild } \\
\text { Mild } \\
\text { Severe } \\
\text { Severe } \\
\text { Mild } \\
\text { Severe } \\
\text { Severe } \\
\text { Severe } \\
\text { Severe } \\
\text { Severe } \\
\text { Severe } \\
\text { Mild } \\
\text { Severe } \\
\text { Severe } \\
\text { Severe }\end{array}$ & $\begin{array}{l}1 \\
2 \\
3 \\
2 \\
2 \\
3 \\
6 \\
1 \\
3 \\
2 \\
5 \\
5 \\
2 \\
1 \\
6 \dagger \\
2 \\
2 \\
2 \\
6 \\
7 \\
2 \\
2 \\
3 \\
4\end{array}$ & $\begin{array}{l}104.4 \\
104.6 \\
104.2 \\
104.4 \\
104.4 \\
105.4 \\
104.6 \\
104.6 \\
102.6 \\
104.6 \\
104.0 \\
104.6 \\
104.6 \\
104.2 \\
102.8 \\
104.8 \\
104.6 \\
104.4 \\
105.2 \\
105.6 \\
104.6 \\
104.6 \\
106.2 \\
105.8\end{array}$ & $\begin{array}{l}5.0 \\
5.0 \\
1.5 \\
0.5 \\
6.0 \\
3.0 \\
3.0 \\
2.0 \\
3.0 \\
2.0 \\
3.0 \\
3.0 \\
3.0 \\
4.0 \\
1.0 \\
1.5 \\
4.5 \\
3.0 \\
2.0 \\
2.5 \\
2.0 \\
3.0 \\
5.0 \\
5.0\end{array}$ & $\begin{array}{r}0 \\
0 \\
1 \\
1 \\
1 \\
0 \\
0 \\
0 \\
0 \\
0 \\
0 \\
0 \\
4 \\
0 \\
4 \\
1 \\
11 \\
0 \\
0 \\
0 \\
0 \\
0 \\
1 \\
0\end{array}$ \\
\hline
\end{tabular}

* Reaction in this animal followed inoculation with bacilli recovered from epidemic typhus Case 5. In all other animals in this series, the reaction was produced by inoculation of typhus blood.

+ Twenty-four hours after crisis.

Of the twenty-four guinea-pigs in this series, in eight, or $33 \frac{1}{3}$ percent, a bacillus was isolated from the blood in pure culture which morphologically and culturally was identical with the one recovered from the blood of individuals with typhus fever. The fact that this percentage of positive blood cultures is lower than that obtained in the work on human cases, is undoubtedly for the most part due to the very small quantities of blood which we were forced to use for culture, the average amount being 3 c.c. 
The febrile reactions at the time when the positive cultures were obtained were proved to be due to typhus fever. In four of these animals (Guinea-pigs 58,65, 69, and 74) the proof was obtained by inoculating blood secured at the same time as the blood culture, into twelve other animals. All developed the disease after the usual incubation period, and, in some of these, immunity to re-inoculation was subsequently demonstrated. The blood of the others was found to be capable of reproducing the typical febrile reaction in normal guineapigs and not in those which had once had typhus fever. The results of the experiments on Guinea-pig 58 and on the three animals inoculated with its blood are presented as examples.

Guinea-Pig 58.-Inoculated intraperitoneally with 2.5 c.c. of defibrinated blood from Guinea-pig 50, diluted with an equal volume of normal salt solution. This was the third passage of the virus originally obtained from epidemic

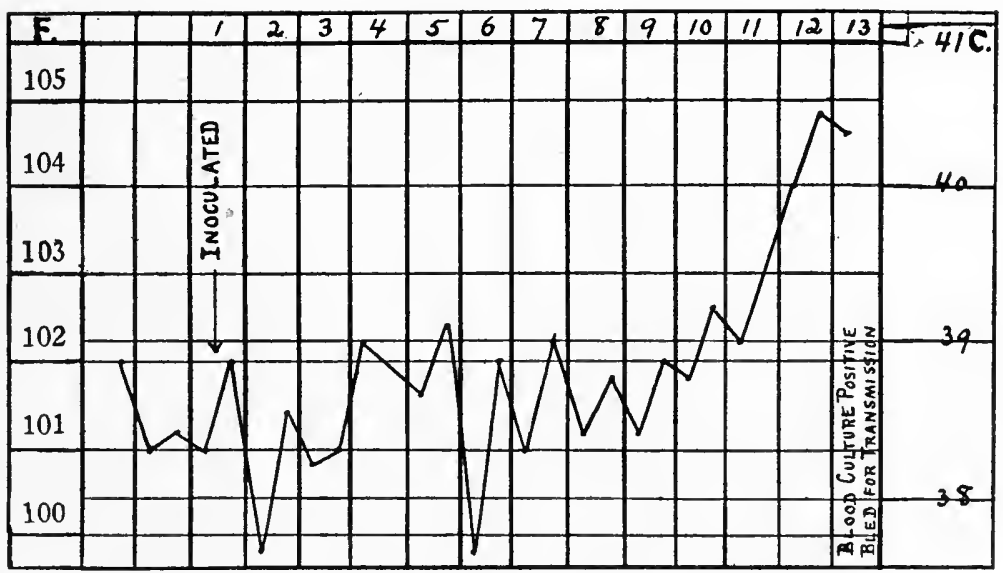

Temperature Curve 1. Guinea-pig 58.

Reaction after inoculation with blood of Guinea-pig 50 (virus from epidemic typhus Case 10). Blood culture positive on second day of fever. Blood infectious for Guinea-pigs 27 and 69 , but not for immune Guinea-pig 5 .

typhus Case 10. The febrile reaction began suddenly on the twelfth day after inoculation. On the second day of the fever, 3 c.c. of blood were aspirated from the heart under aseptic precautions and cultured in two deep tubes of glucose serum agar. Five days later, three typical colonies appeared in one tube, and one in the other. The organisms from all four colonies were found to be both morphologically and culturally identical with the bacillus typhiexanthematici.

Immediately after the blood culture was taken, 9 c.c. of blood were obtained from the animal's carotid artery; 3 c.c. of this blood, diluted with an equal vol- 
ume of salt solution, were injected intraperitoneally into two normal guineapigs, 27 and 29, and into an immune animal, Guinea-pig 5. Post mortem, no changes were discoverable in any organ except the spleen, which was enlarged, as a result of a hypertrophy of the Malpighian bodies.

Guinca-Pigs 27 and 69.-The temperature charts of Guinea-pigs 27 and 69 are supplied in place of detailed results. On the third day of the disease, both animals were bled from the carotid and their blood was found to be infectious for four normal guinea-pigs, but not infectious for a typhus-immune animal.

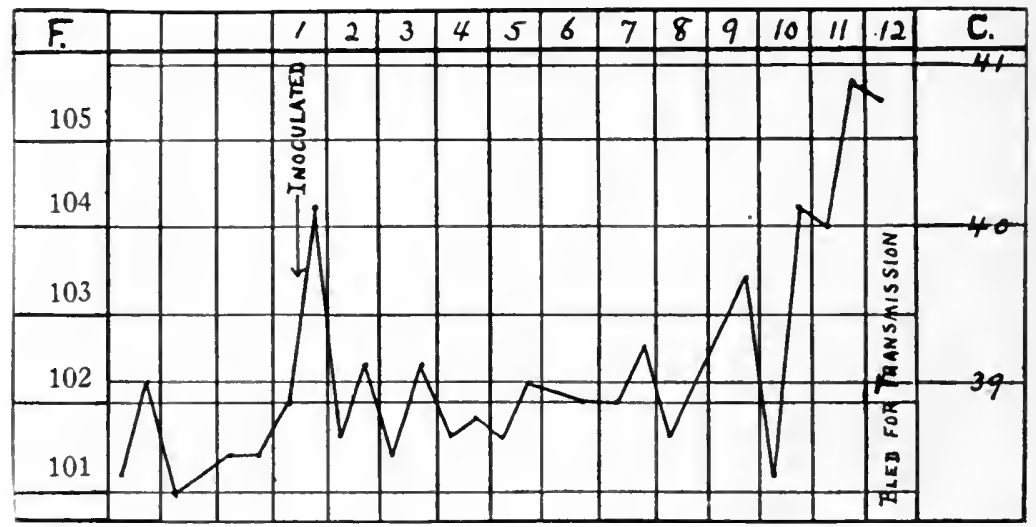

Temperature Curve 2. Guinea-pig 27.

Inoculated with blood from Guinea-pig 58. Blood infectious for other guinea-pigs.

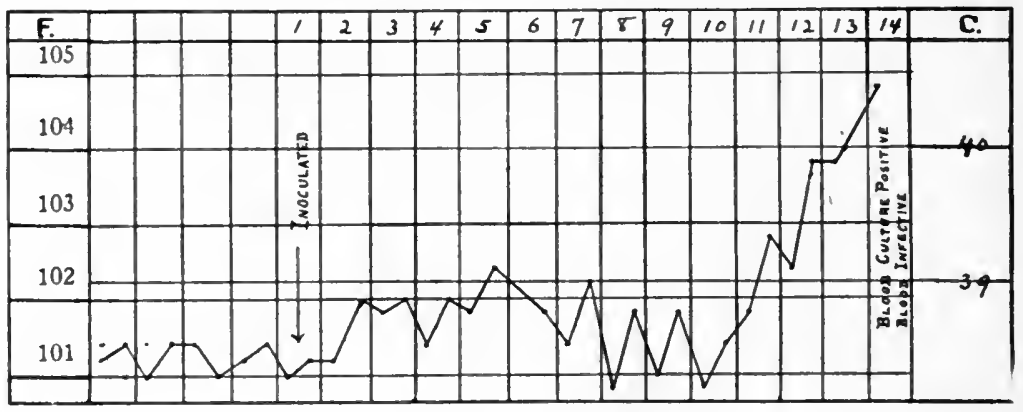

Temperature Curve 3. Guinea-pig 69.

Inoculated with blood from Guinea-pig 58. On the third day of reaction, blood culture positive and blood infectious for other guinea-pigs.

The postmortem findings were the same as in Guinea-pig 58. From 1.5 c.c. of blood obtained by cardiac puncture from Guinea-pig 69 before the transmission experiment, one colony of the bacillus typhi-exanthematici was grown.

Guinea-Pig 5.-This animal had first been inoculated with 4 c.c. of defibrinated blood from epidemic typhus Case 4. It passed through a typical febrile 
reaction (see temperature chart) and had completely recovered before it was used for this experiment. Two months after the first inoculation, it was re-inoculated with 3 c.c. of defibrinated blood from Guinea-pig 58, diluted with an equal volume of normal salt solution. Its temperature was observed twice daily for a period of thirty days thereafter and no febrile reaction occurred as in the control Guinea-pigs, 27 and 69.

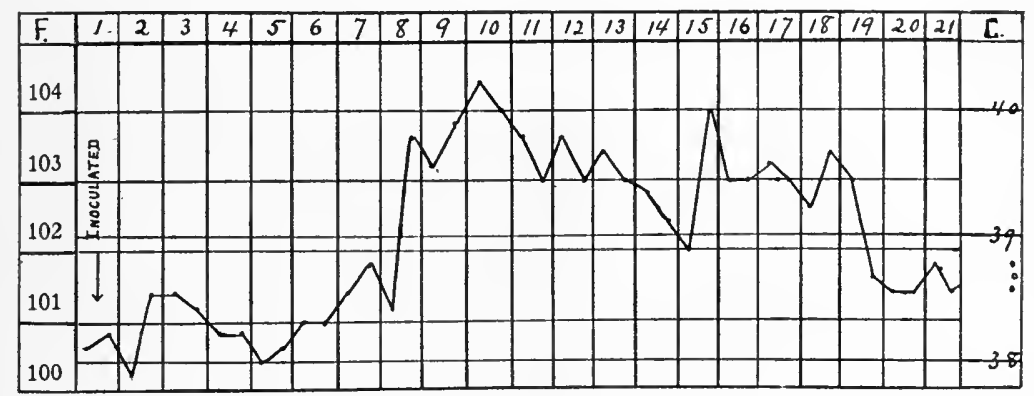

Temperature Curve 4. Guinea-pig 5.

Reaction after inoculation with blood from epidemic typhus Case 4.

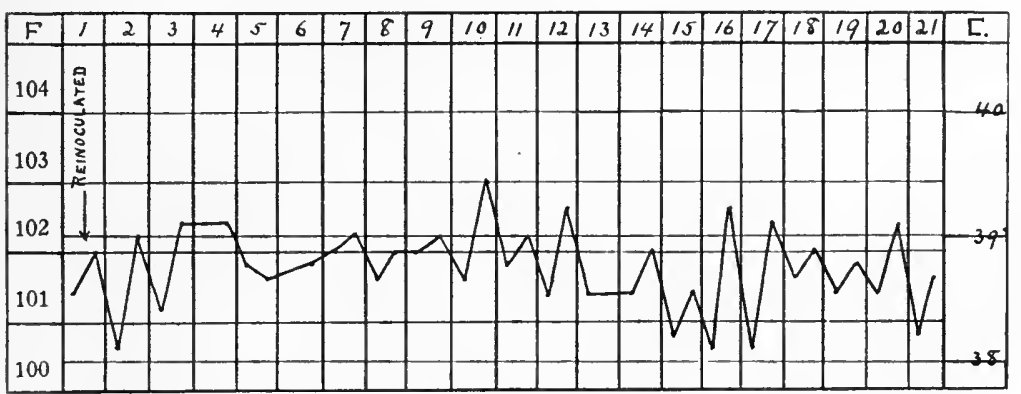

Temperature Curve 5. Guinea-pig 5.

Re-inoculated with blood from Guinea-pig 58. No reaction. (Controlled by Guinea-pigs 27 and 69.)

In Guinea-pig 103, in which the blood culture had been positive, the reaction was proved to be due to typhus fever by subsequently demonstrating that the animal was immune to a re-inoculation of another typhus virus.

Guinea-Pig 103.-Inoculated intraperitoneally with 3 c.c. of defibrinated blood obtained from Guinea-Pig 63 at the height of the disease and diluted with an equal volume of normal salt solution. The virus had originally been obtained from epidemic typhus Case 10 and since that time had been transmitted through six guinea-pigs. Guinea-pig 103 developed the typical febrile reaction after an incubation period of fourteen days. On the third day of the disease, when 


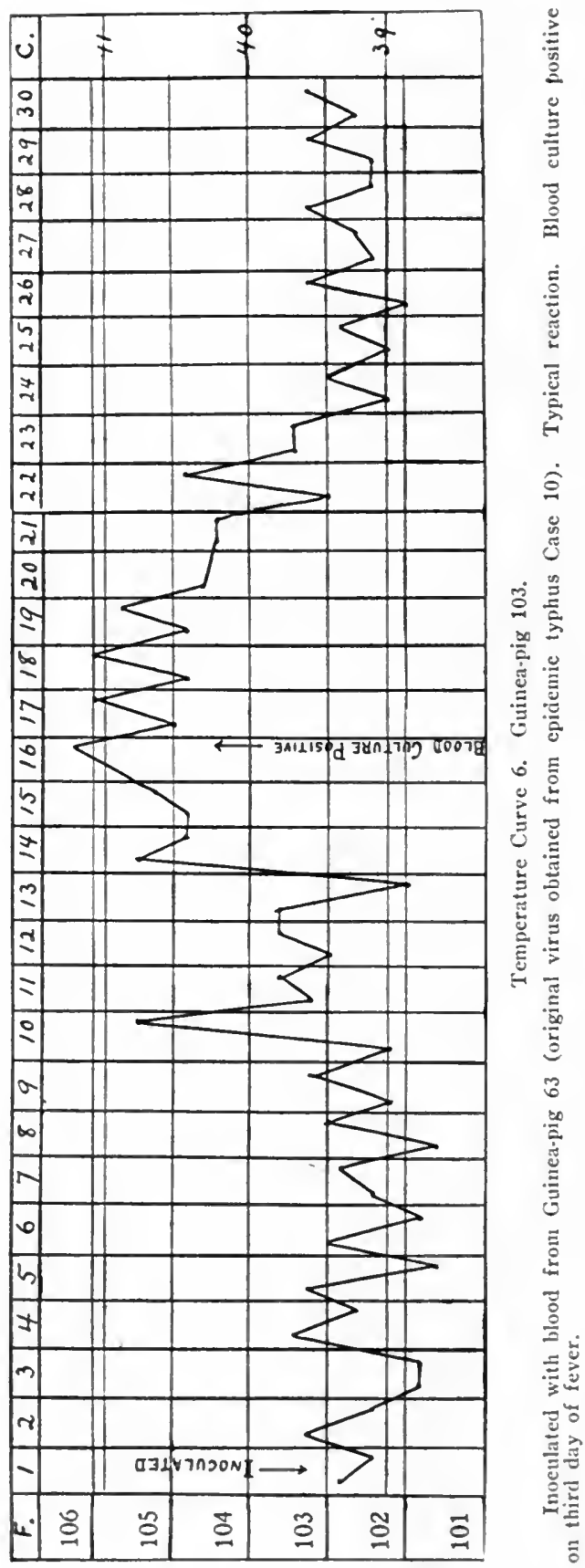


the temperature was $106.2 \mathrm{~F}$. (41.2 C.), a blood culture taken in the usual manner was positive. Five months after the termination of the illness, the animal was re-inoculated with 3.5 c.c. of defibrinated blood obtained from Guinea-pig 244 at the height of its disease and diluted with an equal volume of saline solution. This virus had been obtained by Anderson and Goldberger ${ }^{6}$ three and a half years previously from an endemic case in the wards of the Mount Sinai Hospital and since that time it had been transmitted through many generations of monkeys and guinea-pigs.

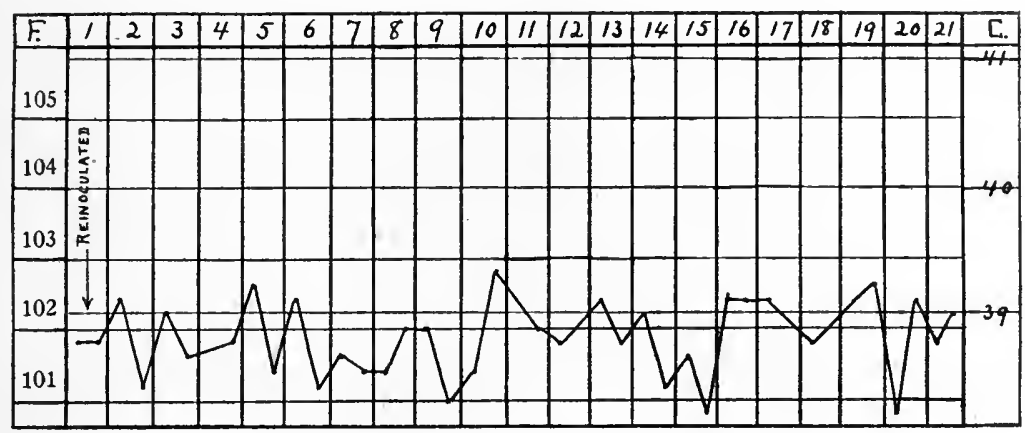

Temperature Surve 7. Guinea-pig 103.

Re-inoculated with blood from Guinea-pig 244 (endemic typhus Case W). No reaction, the previous illness having conferred immunity to typhus virus. Three control guinea-pigs developed typical febrile reactions.

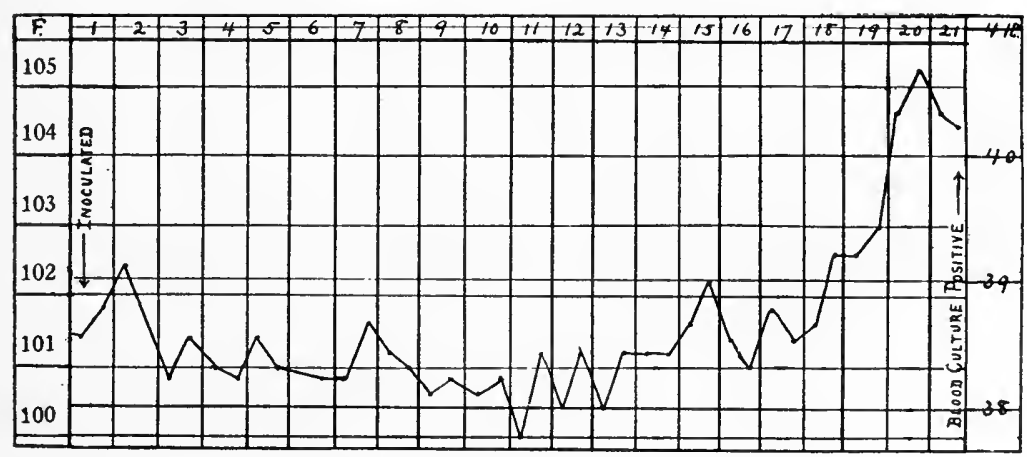

Temperature Curve 8. Guinea-pig 24.

Inoculated with blood from epidemic typhus Case 10. Blood culture positive on second day of fever.

As seen in Temperature Curve 7, the animal proved resistant to this re-inoculation, altho three other control guinea-pigs, inoculated simultaneously with an equal amount of the blood, developed marked febrile reactions. The temperature observations were kept up for thirty-five days after the re-inoctlation. 
Of the other three animals with positive blood cultures, the reaction in Guinea-pig 16 was produced by the intraperitoneal injection of virulent bacilli. The reactions in Guinea-pigs 21 and 24 were produced by the injection of blood from epidemic typhus Case 10, which was also infectious for other guinea-pigs, producing in them the typical febrile reaction followed by immunity. As an example, see Temperature Curves 6 and 7 of Guinea-pig 103.

Therefore, in the eight animals with positive blood cultures, there can be no doubt that the febrile reactions were due to typhus fever.

Of the animals with negative blood cultures, Guinea-pig 13 was bled from the carotid immediately after the blood culture and this blood was inoculated into Guinea-pigs 61,70 , and 72 (3 c.c. into each). None of these animals developed the disease. Apparently, therefore, no viable bacilli were present in the blood of Guinea-pig 13 and this explains the negative result of the culture.

Blood from six other animals with negative blood cultures (Guinea-pigs 55, 56, 63, 75, 85, and 87) was inoculated into another series of thirteen guinea-pigs and all in this series developed the disease. This apparent discrepancy with the blood culture results possibly may have been due to the small quantity of blood used in the cultures. As will be shown later, in the inoculation experiments made with human blood, larger amounts were always available for culture and the blood culture results were therefore more accurate. In those experiments no such discrepancy between the blood culture results and the infectivity of the blood was ever noted.

In the positive blood cultures, the colonies averaged about one in a cubic centimeter of blood. This is more than was found in the patients with endemic typhus fever, but less than in individuals with epidemic typhus.

Blood cultures were also made on four monkeys in which the disease had been produced by inoculation with the blood of typhus guineapigs, 1-4 c.c. being used in each instance. In one monkey (B 1) the blood culture was positive.

Monkey $B$ 1.-Inoculated intraperitoneally with 5 c.c. of defibrinated blood from Guinea-pig 247, diluted with an equal volume of normal salt solution. The original virus was the one obtained by Anderson and Goldberger ${ }^{\circ}$ three and a half years before from an endemic case. As a control, Guinea-pig 248 was also inoculated with 3 c.c. of the blood of Guinea-pig 247 and it developed the disease after a nine-day incubation period. In Monkey B 1, the disease began suddenly on the eighth day of the experiment. 
On the third day of the fever, when the temperature reached $105.4 \mathrm{~F} .(40.8 \mathrm{C}$.), 5.5 c.c. of blood were aspirated from a vein in the leg under aseptic precautions. Two cubic centimeters of this were cultured in two deep tubes of glucose serum agar, and in one of the tubes one colony appeared five days later. The organisms from this colony proved to be morphologically and culturally identical with the bacillus typhi-exanthematici. Three and one-half cubic centimeters of the blood were inoculated intraperitoneally into Guinea-pig 256. After an incubation period of sixteen days, it developed a characteristic febrile reaction which lasted six days.

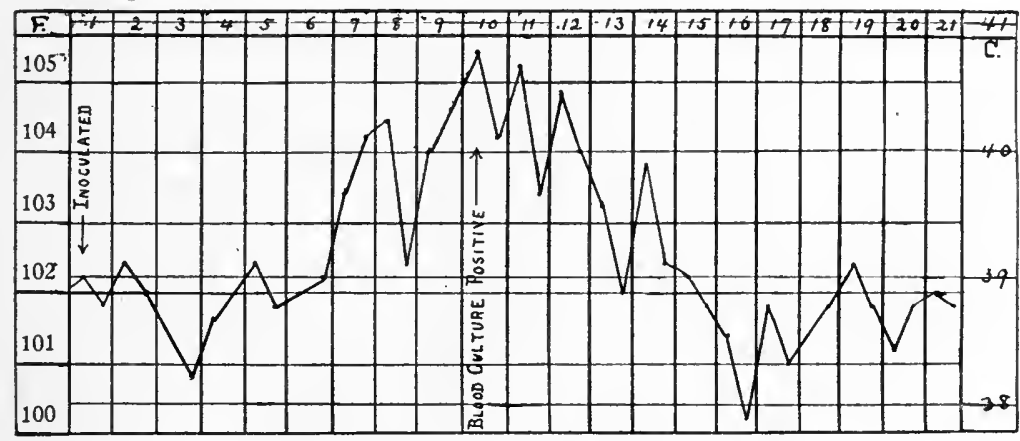

Temperature Curve 9. Monkey B 1.

Inoculated with blood from Guinea-pig 247. Original virus had been obtained from a patient with endemic typhus fever three and a half years before. Blood culture positive on fourth day of fever.

This experiment is of importance because it demonstrates that in monkeys with typhus fever the same bacillus can also be isolated from the blood. Of especial interest is the fact that the virus with which this monkey was infected was the one obtained by Anderson and Goldberger $^{6}$ from a patient with endemic typhus fever three and a half years before.

\section{RELATION OF BLOOD CULTURES TO THE SEVERITY OF THE DISEASE}

Of nine guinea-pigs with mild febrile reactions, in only one was the blood culture positive. On the other hand, in fifteen animals with severe reactions, the blood culture was positive in seven, or almost 50 percent. This relation between the blood cultures and the severity of the disease was also observed in the human typhus cases (q. v.). It is undoubtedly very suggestive as to the causal relationship of the bacterium to the disease. 
TABLE 2

Relation of Blood Cultures to the Stage of the Disease

\begin{tabular}{c|c|c}
\hline Day of Culture & $\begin{array}{c}\text { Number of Animals } \\
\text { Cultured }\end{array}$ & Number of Positive Blood \\
Cultures
\end{tabular}

As the table indicates, blood cultures taken on the second and third day of the disease (that is $24-72$ hours after the onset) were positive in 50 percent of the animals.

In this series of experiments also, the blood cultures were purposely taken at different stages of the disease, as outlined in Table 2.

- This observation assumes especial interest when the temperature curves of thirty-five other animals, which were permitted to live for the entire course of their disease, are analyzed. Of this series, the highest temperature was reached during the first twenty-four hours in two animals, on the second day in twelve, on the third day in eleven, on the fourth day in seven, on the fifth day in two, and on the sixth day in one animal.

In the majority of instances (66 percent), therefore, the fever reached its highest point on the second or third day of the disease, in other words, 24-72 hours after the onset. (Anderson' ${ }^{2}$ reports that, in his guinea-pig experiments, the highest temperature was usually reached 36-72 hours after the onset.) This is the period when in the infected animals the blood culture is most frequently positive. It is still another demonstration of the relation between the severity of the disease and the numerical frequency of the organisms in the circulating blood.

\section{POSITIVE BLOOD CULTURES AFTER THE CRISIS}

Guinea-pig 65 of the blood culture series requires special mention because of the fact that the positive blood culture was obtained 24-36 hours after the crisis.

Guinea-Pig 65.-Inoculated with 3 c.c. of defibrinated blood obtained from Guinea-pig 68 on the third day of the disease. The blood was diluted with an equal volume of normal salt solution before injection. The original virus had been obtained from epidemic typhus Case 10 and since that time had been transmitted through four successive guinea-pigs. The fever began suddenly on the fourteenth day of the experiment and lasted five days. 
A blood culture was taken 24-36 hours after the crisis, when the temperature was normal. From 1 c.c. of blood used for the culture, four colonies were grown, a proportionately larger number than in any of the blood cultures in the other animals of the series. When 3.5 c.c. of blood, obtained at the same time as the blood for culture, were injected intraperitoneally into Guineapig 98, it developed a typical reaction after an incubation period of seven days.

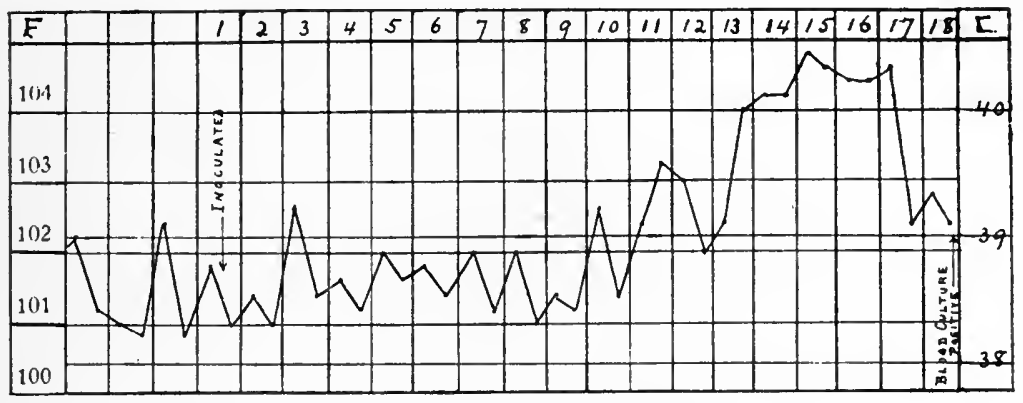

Temperature Curve 10. Guinea-pig 65.

Reaction after inoculation with blood from Guinea-pig 68. Crisis on fifth day of fever. Blood culture positive $24-36$ hours after crisis.

The finding of viable bacteria in the blood of an animal 24-36 hours after the crisis is in accord with the observations recorded by Dr. Plotz in his paper of the presence of bacilli in the blood of two typhus patients, 12 and 36 hours after the crisis. Nicolle and Consei ${ }^{98}$ believed the blood to be infective $36-48$ hours after the crisis, but their observations are not convincing. Anderson and Goldberger ${ }^{16}$ have found the blood to be infective for animals 12 and 32 hours after the crisis. In our animal, not only was the blood culture positive 2436 hours after the crisis, but 3.5 c.c. of blood obtained at the same time were infective for Guinea-pig 98. After an incubation period of seven days, Guinea-pig 98 ran a typical febrile course, reaching as high as 105.2 F. (40.7 C.) and lasting six days.

The observation of the presence of bacilli in the blood 24-36 hours after the crisis, and the finding that the blood is still infective during this time, are important for several reasons. First, it completely eliminates the possibility that the crisis in typhus fever may be due to a sudden destruction of the bacteria. The critical ending of the disease is therefore most probably due to the final consummation of a cellular immunity on the part of the body to the bacilli. In some cases, at least, it is only later with the subsequent development of bacterial antibodies during the $24-48$ hours after the crisis that the bacilli themselves are eventually killed off. (During the precritical stage of the disease, 
probably the chief factors tending to limit the multiplication of the bacilli are opsonization and phagocytosis, as has been suggested in the preceding section of this paper.) This explanation of the mechanism of the crisis in typhus fever also received substantial confirmation in the serologic studies of Dr. Olitsky. He was actually able to demonstrate that, in many instances in men and monkeys, the specific bacterial antibodies (agglutinins, precipitins, complement-fixation bodies, etc.) only begin to appear in the blood during the first few days after the crisis.

The demonstration of the presence of bacilli in the blood and its infectivity for so long a time after the crisis is also of interest from another standpoint. It indicates that, during this early period of convalescence, the patient may be a bacillus carrier and hence may still be a source from which infection can spread.

\section{PATHOGENICITY OF THE BACILLI FROM EPIDEMIC TYPHUS CASES}

Two strains of bacilli obtained from two of the epidemic typhus cases (epidemic typhus Cases 1 and 5) were inoculated intraperitoneally into guinea-pigs. In each instance the material used for the inoculation consisted of a subculture of the organism, which had grown on a slant of 0.5 percent glucose ascitic fluid agar in a Buchner tube for three days. The growth was scraped from the surface of the slant with a platinum loop and emulsified in 2 c.c. of normal salt solution. This represented the inoculated dose.

In epidemic typhus Case 1, the colonies did not appear in the blood culture tubes until the fourteenth day, so that including the time subsequently consumed in the identification and study of the organism, the bacilli were out of the body for thirty-three days before they were inoculated into Guinea-pig 8. The organism recovered from epidemic typhus Case 5 was out of the body sixteen days before it was inoculated into Guinea-pig 16. (Guinea-pigs 8 and 16 were isolated in individual cages which were separated from one another and fron! all other animals by wooden partitions.)

During the first twenty-four hours after the inoculation, the animals developed a slight, transient elevation in temperature, the significance of which will be discussed later. The temperature of Guinea-pig 8 then remained normal, that is, below $102 \mathrm{~F}$. (38.8 C.) until the sixti day after inoculation, when a sudden rise to $104 \mathrm{~F}$. (40 C.) occurred. The animal then ran a febrile course similar to that of animals after inoculation with the blood of typhus patients. The temperature 
remained about $104 \mathrm{~F}$. (40 C.) for four days and then gradually fel! to normal, reaching $102 \mathrm{~F}$. (38.8 C.) two and a half days later. During the next five days the temperature remained normal, that is, below 102.4 F. (39 C.).

In order to test its immunity, the animal was then re-inoculated with 3 c.c. of defibrinated blood obtained from epidemic typhus Case 10 , and died several hours later as a direct result of the inoculation.

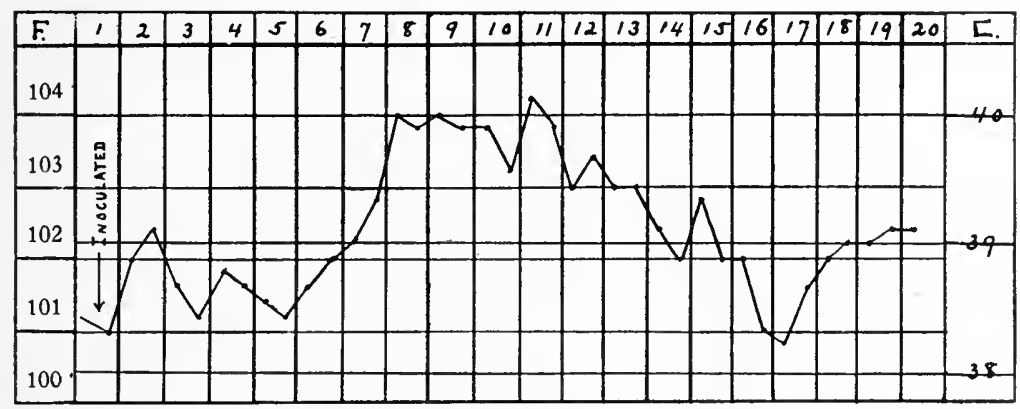

Temperature Curve 11. Guinea-pig 8.

Reaction after inoculation with bacteria (strain from epidemic typhus Case 1).

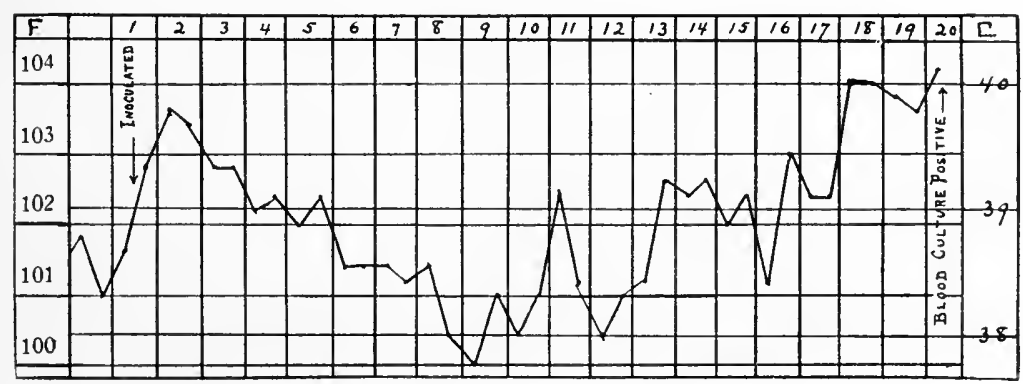

Temperature Curve 12. Guinea-pig 16.

Reaction after inoculation with bacteria (strain from epidemic typhus Case 5). Bacteria recovered irom blood during reaction.

Unfortunately this was very early in our work when we had not yet learned to delay re-inoculation until the animal had recovered its full weight and strength.

The result obtained with Guinea-pig 16 was still more striking. After an incubation period of eighteen days, it developed a sudden rise of temperature to $104 \mathrm{~F}$. ( $40 \mathrm{C}$.). The fever continued at about this level, and on the third day after the onset a blood culture was made. 
After epilation and disinfection of the skin over the ventral aspect of the thorax in the usual manner, 1.5 c.c. of blood were aspirated from the heart and cultured in two deep tubes of 2 percent glucose ascitic fluid agar. The animal died shortly after the operation of intrapericardiac hemorrhage.

At autopsy, no anatomic or histologic lesions were found in any organ except the spleen. The latter was enlarged to two or three times its normal size; the Malpighian bodies were markedly hypertrophied so that they were easily visible macroscopically. These are the lesions which we have always found in guinea-pigs which have been killed, or have died, during the course of a typhus fever. Ricketts and Wilder have regarded the absence of any pathologic lesion in any of the viscera as characteristic of typhus fever in the monkey. But in our numerous experiments with the guinea-pig, altho all other viscera remained microscopically, as well as macroscopically normal, we have never failed to find a marked enlargement of the spleen, due chiefly to a hypertrophy of the Malpighian bodies.

Seven days after the blood culture was made, a characteristic colony appeared in one of the culture tubes. This organism upon subculture proved to be both morphologically and culturally identical with Bacillus typhi-exanthematici.

These experiments prove that bacilli recently isolated from epidemic cases of typhus fever are pathogenic for guinea-pigs. They further demonstrate that with such organisms a disease can be produced in these animals which in its incubation period and its febrile course is similar to typhus fever as reproduced in guinea-pigs by the inoculation of typhus blood. And finally, what is perhaps most important, they demonstrate that during the febrile period of the disease an organism identical with that which was inoculated can be recovered from the circulating blood.

\section{LOSS CF VIRULENCE AFTER ISOLATION}

Other guinea-pigs and monkeys were subsequently inoculated with the two strains of bacilli used in the experiments just described (epidemic typhus Cases 1 and 5) after the strains had been retransplanted on slants of 2 percent glucose ascitic fluid agar a number of times; both strains were then found to have completely lost their virulence. Three other strains of organisms, from epidemic typhus Cases 2, 4, and 6, after they had been on artificial media for more than three or four 
weeks, were also inoculated into guinea-pigs and monkeys, with negative results. In each instance the inoculation was followed only by a slight, transitory rise in temperature during the first twenty-four hours, a reaction also observed in the experiments with virulent organisms.

The regular occurrence of this rise in temperature during the first twenty-four hours after inoculation of epidemic typhus organisms we believe to be due to the absorption of bacterial endotoxins. If, before the inoculation, the organisms were suspended for one-half to one hour in a $1: 20$ to $1: 100$ dilution of typhus immune serum, that is, serum from an individual convalescent from typhus fever, no such rise in temperature occurred. This was considered as evidence of a neutralization of the bacterial toxin by an antitoxin in the immune serum. After cultivation on artificial media for more than a month, all strains of epidemic typhus organisms also lost this toxic action.

In spite of repeated attempts by passages through mice and guineapigs, it was found impossible to restore the virulence of any of the strains after they had once lost it. Other attempts were made by growing the organism in citrated blood and in magnesium carbonate broth, but these were unsuccessful.

This rapid loss of virulence explains why the reproduction of typhus fever in animals by inoculation of the bacilli was not done more extensively. The positive blood cultures in cases of epidemic typhus fever were obtained at the very beginning of the work. Subsequently, when the importance of inoculating the organisms into animals within the shortest possible time after isolation was realized, no more cases of epidemic typhus fever were available.

We hope to have the opportunity very shortly to amplify this phase of the work. It is important, however, that we have demonstrated that with bacilli recently isolated from epidemic cases of typhus fever the disease can be reproduced in animals, and that at the height of disease so produced the identical organism can again be recovered from the blood.

\section{VIRULENCE OF BACILLI FROM ENDEMIC CASES}

Experiments carried out with six strains of bacilli from the endemic typhus cases (Cases 1, 2, 18, 23, 27, and 40) and with those isolated from three animals (Guinea-pigs 21, 24, and 103) with typhus fever, revealed the fact that they lost their virulence outside the body still more rapidly than did the epidemic typhus strains. Before suffi- 
cient growth could be obtained for inoculation, the organisms were on artificial media for two to three weeks, or even longer. When finally ready for inoculation, such organisms were not only avirulent, but they did not eren possess the power of producing a toxic rise in temperature after inoculation, a property only lost by the epidemic typhus organisms after cultivation for over a month.

Both morphologically and culturally the organisms isolated from the epidemic and the endemic types of the disease proved to be identical, and both were found to possess the same specific antigenic properties. This variation in virulence and in toxin production is the only essential difference which we have been able to demonstrate between the organisms derived from the two sources. Its importance lies in that it supplies us with a possible reason for the difference in the degree of bacteriemia and in the severity of the two diseases.

\section{RELATION゙ BETWEEN THE N゙UMBER OF BACILLI IN TYPHUS BLOOD}

\section{AND ITS INFECTIVITY}

The observations presented thus far in this section of our report have demonstrated the association of the bacillus recovered from cases of typhus fever with the disease as reproduced in the experimental animals. Further evidence from the experimental standpoint that this organism is the etiologic agent in typhus fever was readily obtained by a study of the relation between the number of the bacilli in typhus blood and its infectivity.

In this series of experiments, eight monkeys and forty-three guinea-pigs were inoculated with blood obtained from twenty-three endemic cases of typhus fever and five epidemic cases. The blood for inoculation was obtained at the same time as the blood for culture and frequently with the same syringe. After defibrination, 2-9 c.c., diluted with an equal volume of normal salt solution, were injected intraperitoneally into each animal. The blood from the endemic cases was, as a rule, injected within half an hour after it was obtained. The blood from the epidemic cases had to be carried from the quarantine station on Swinburne Island, New York, and was sometimes out of the body as long as three or four hours.

In Table 3, Column 5 , is listed the average number of organisms apparently contained in the quantity of blood inoculated into each animal. This was estimated from the total number of bacterial colonies which developed in the blood culture tubes. It is quite pos- 
sible that some organisms may have lodged in the upper $3-5 \mathrm{~cm}$. of the column of medium and may not have multiplied because of the incomplete anaerobiosis. Also, as soon as a tube is broken open and a subculture of a colony made, those colonies which may have appeared subsequently are lost. Upon analysis, however, the latter source of error in the statistics is found to be relatively slight. For altho the time when the colonies became visible in the different blood cultures varied from three to sixteen days, in each individual culture all the

TABLE 3

Relation of Number of Organisms (as Determined by Blood Culture) to Infectivity OF BLOOD

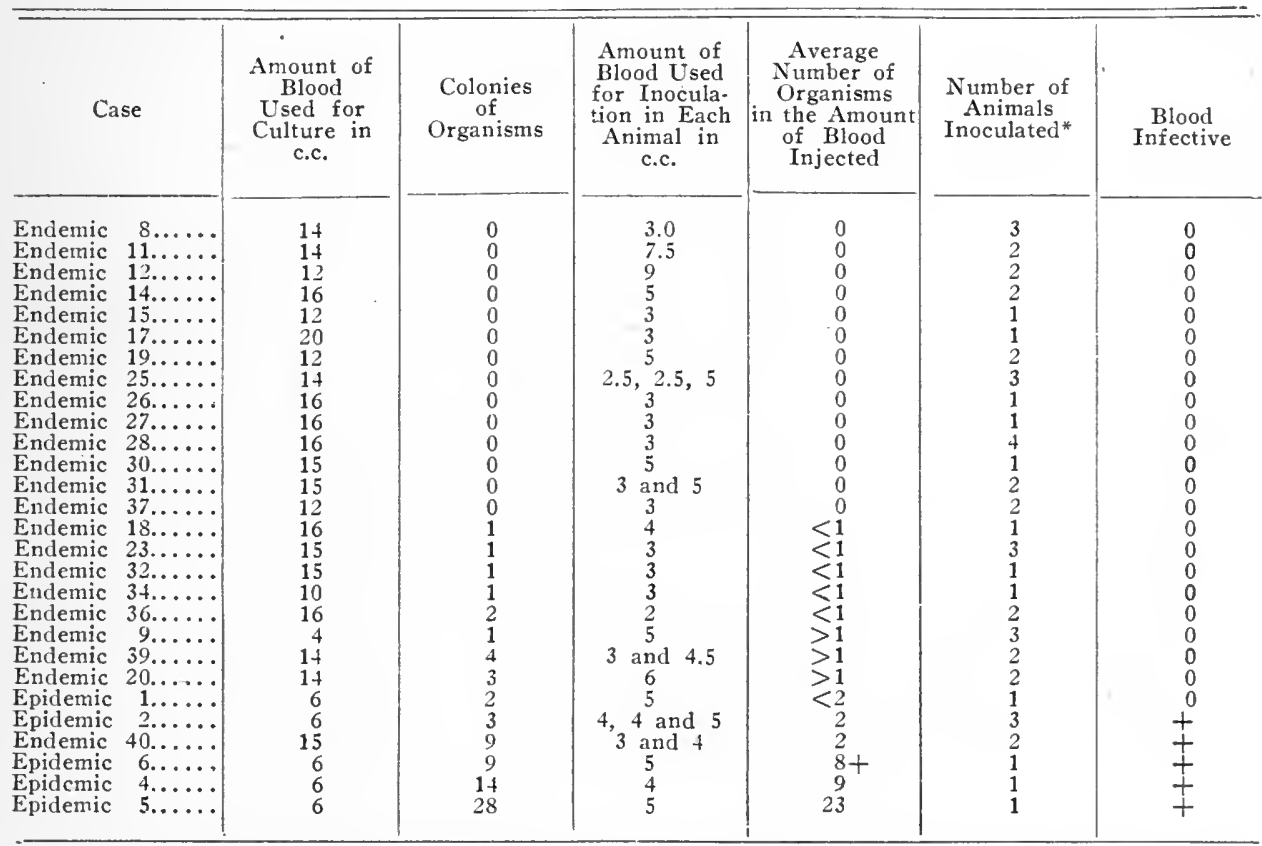

* One monkey was used in each of the series of experiments made with blood from endemic typhus Cases $25,28,30,31,39,40$, and epidemic typhus Cases 1 and 2 . All the other animals listed in this column were guinea-pigs.

colonies usually appeared in the tubes within twenty-four to forty-eight hours. Tubes were seldom opened until seventy-two hours after the first colonies appeared.

In fourteen of the twenty-eight cases in this series, the blood cultures were negative, altho large amounts of blood were used, 12-20 c.c. Blood from these patients, in quantities ranging from 2.5 to 9.0 c.c., 
was likewise inoculated into twenty-seven animals, four monkeys and twenty-three guinea-pigs. None of the animals developed a febrile reaction. Nor was immunity ever produced, for all the animals reacted in the typical manner to a subsequent re-inoculation of active typhus blood.

In the other fourteen cases, the blood cultures were positive, the number of colonies developing in the different cultures ranging from one to twenty-eight. In nine of these fourteen patients (endemic typhus Cases 9, 18, 20, 23, 32, 34, 36, 39, and epidemic typhus Case 1). the blood cultures contained relatively few colonies, so that the estimated number of bacilli in the quantities of blood injected averaged less than two. Sixteen animals, two monkeys and fourteen guineapigs, were inoculated with blood from these patients. In no instance did the inoculation result in a febrile reaction or in an immunity.

In the remaining five patients (epidemic typhus Cases $2,4,5,0$, and endemic typhus Case 40), the blood cultures showed the organisms to be more numerous. The average number of bacilli estimated as present in the quantities of blood used for the animal inoculations ranged from two to twenty-three. The blood from all five cases was found to be infective for animals. After the characteristic incubation period, the animals ran a typical febrile course.

The experiments carried out with the blood of epidemic typhus Case 2 is especially interesting. Of the five typhus patients whose blood was infective, the blood from this patient apparently contained the fewest organisms. It contained proportionately slightly more organisms, however, than epidemic typhus Case 1, or endemic typhus Case 20 , the blood from which was not infective. Into each of two guineapigs (Guinea-pigs 2 and 3) 4 c.c. of blood were inoculated and 5 c.c. into a monkey (Monkey A 2). The monkey did not react. Both guinea-pigs developed exceedingly mild, tho quite definite, febrile react:ons.

Guinear-Pig 2.-After the inoculation with blood from epidemic typhus Case 2, the temperature remained normal until the seventh day, ranging between $101 \mathrm{~F} .(38.4 \mathrm{C}$.) and $102 \mathrm{~F} .(38.8 \mathrm{C}$.$) . On the seventh day after inoculation,$ it rose abruptly to $103.2 \mathrm{~F}$. (39.5 C.) and remained about this level for five days. The highest temperature $103.8 \mathrm{~F}$. (39.9 C.) was reached on the third day after the onset. On the fifth day the temperature fell to normal, $102 \mathrm{~F}$ (38.8 C.), and remained so for eight days, when the animal died immediately after a re-inoculation. with typhus blood. 
Guinea-Pig 3.-Temperature normal, about 101 F. (38.4 C.), until the sixth day after inoculation, when it rose to $102.2 \mathrm{~F}$. (39 C.). Eight days after inoculation, it rose suddenly to $103.6 \mathrm{~F}$. $(39.8 \mathrm{C}$.) and remained high for four days. After the defervescence of the fever by rapid lysis, the temperature remained below $101.8 \mathrm{~F}$. (38.8 C.) for three weeks.

Altho neither animal was tested for its immunity, the febrile reactions in both were undoubtedly due to typhus fever. They occurred in both guinea-pigs after the characteristic incubation period, seven and eight days respectively, and ran a typical course.

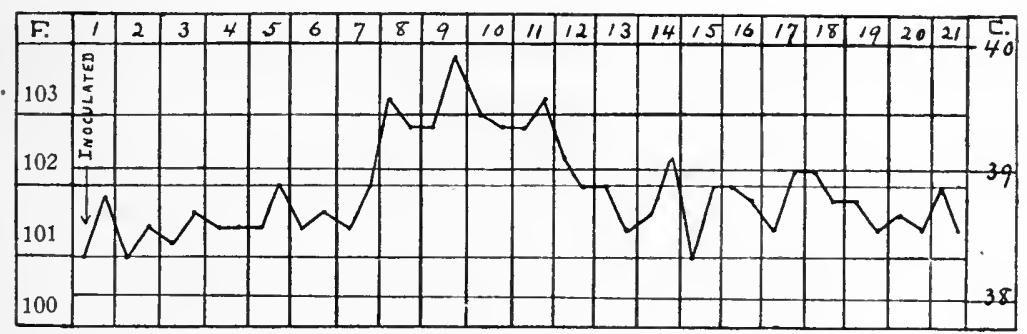

Temperature Curve 13. Guinea-pig 2.

Reaction after inoculation with blood from epidemic typhus Case 2.

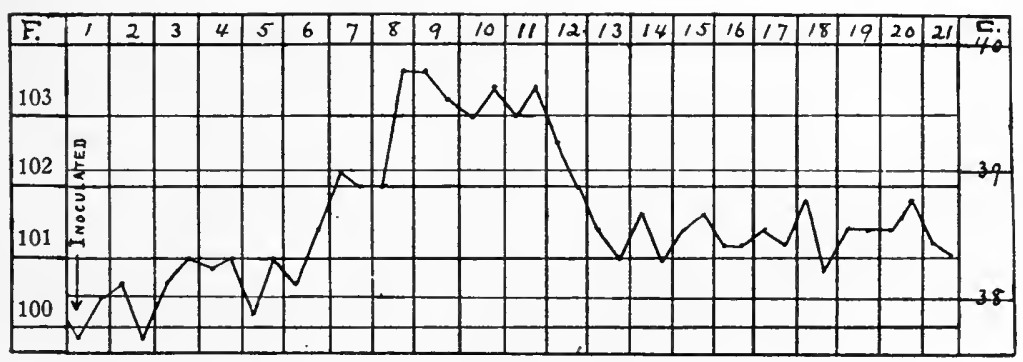

Temperature Curve 14. Guinea-pig 3.

Reaction after inoculation with blood from epidemic typhus Case 2.

The fact that the monkey did not react does not necessarily indicate that it is less susceptible to the disease than the guinea-pig. For it is not improbable that the 5 c.c. of blood injected into the monkey may perchance have contained fewer organisms than the 4 c.c. injected into the guinea-pigs.

The following reports of the two experiments carried out with the blood of endemic typhus Case 40 are supplied as additional examples of temperature reactions in this series. 
Monkey $B$ 7.-Inoculated intraperitoneally with 4 c.c. of blood obtained from endemic typhus Case 40 five days before the crisis. The blood was defibrinated and diluted with an equal volume of normal salt solution before injection. Following the inoculation, the temperature remained normal until the ninth day of the experiment. On the fifteenth day of the experiment, when the temperature was $105.4 \mathrm{~F}$. (40.8 C.), the animal was bled, 5.5 c.c. of blood being obtained. Two and a half cubic centimeters injected into Guinea-pig 229 resulted in a febrile reaction after an incubation period of sixteen days, and the blood during this period was found to be infectious for three other guineapigs. Three cubic centimeters injected into Monkey B 5 failed to produce a febrile reaction.

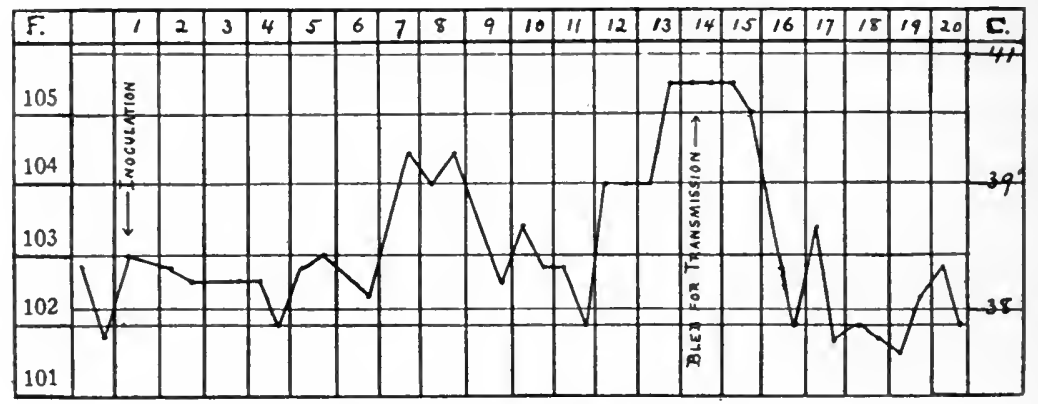

Temperature Curve 15 Monkey B 7 .

Reaction after inoculation with blood from endemic typhus Case 40.

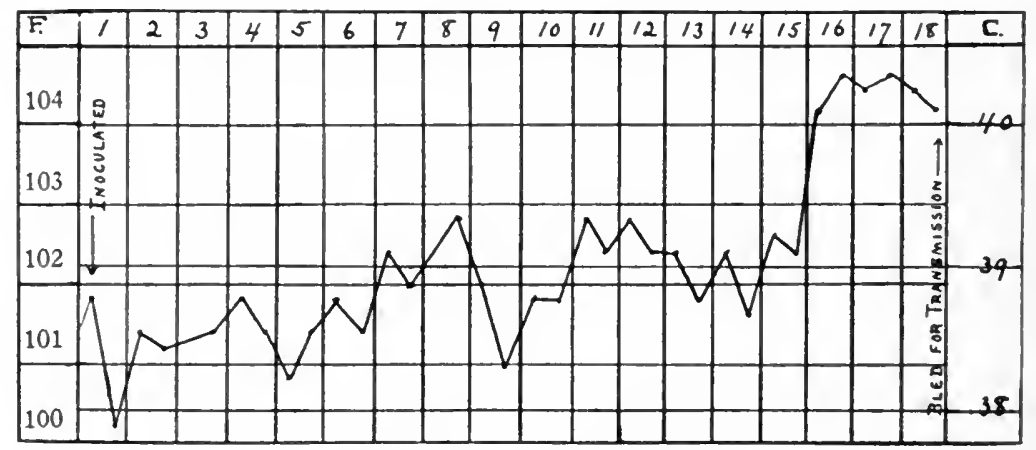

Temperature Curve 16. Guinea-pig 277.

Reaction after inoculation with blood from endemic typhus Case 40.

Guinea-Pig 277.-Inoculated intraperitoneally with 3 c.c. of blood obtained from endemic typhus Case 40, defibrinated and diluted as in experiment on Monkey B 7. On the sixteenth day of the experiment, the temperature rose suddenly to $104 \mathrm{~F}$. (40 C.).

On the fourth day after the onset of the fever, the animal was bled to death from the carotid. Post mortem, the spleen was found to be almost three times the normal size and the Malpighian bodies were very prominent. All other viscera appeared normal. 
With the blood of Guinea-pig 277, the disease was reproduced in three other animals and eventually transmitted through nine generations of guinea-pigs. Some of these animals were subsequently found to be resistant to an inoculation of another typhus virus. In others, the blood during the febrile period was found to be infectious for normal guinea-pigs but not for animals which had once had the disease.

Because of the possibility that all the viable organisms in the blood may not have developed into colonies on culture, we can not commit ourselves to an expression of opinion as to the degree of accuracy of the statistics in Columns 3 and 5 of Table 3 . Nor is it possible to ascertain just how many bacilli constitute the minimal infecting dose. But even if we merely view the results of these experiments most conservatively as comparative observations, they are still of great significance.

The uniformity of the twenty-eight observations tabulated in Table 3 clearly indicates that typhus blood which contains no bacilli, or only very few bacilli, is not infective for animals. Typhus blood in which the bacilli are more numerous is infective. These experiments therefore demonstrate that infectivity is absolutely dependent upon the presence of a sufficient number of these bacilli. This in itself is conclusive evidence of their etiologic significance.

\section{SIGNIFICANCE OF RESULTS OF THE FOREGCING OBSERVATIONS FOR}

THE PROBLEM OF LOUSE TRANSMISSION

The question naturally arises as to the significance of the results of the bacteriologic and experimental observations for the problem of louse transmission. We ourselves have not been able to carry on any experiments with lice. But at least two of the observations manc in the preceding studies-the fact that the organism is a bacillus and that it nccurs in the blood in typhus fever only in relatively small numbers - have considerable bearing upon some of the still obscure phenomena of louse transmission.

The presence of so few bacilli in the blood must render it relativeiy difficult for lice to become infected. That this is true is evidenced by the great difficulty which previous workers have experienced in transferring an infection experimentally by means of lice. If the experiments of previous workers ${ }^{16}, 02,08,131$ are analyzed, the striking feature is seen to be the fact that large numbers of lice, often more than one hundred, were necessary in order to transfer the disease. These lice were usually fed upon infected individuals a number of 
times before they were used for the experiments. Even under these conditions, usually no fever or other manifestations of the disease were produced, the only proof that a transfer of virus had occurred being the subsequent demonstration of an immunity to re-infection.

Thirty-seven lice fed on an infected individual on two successive days is the minimal number with which it has thus far been possible to reproduce experimentally the typical febrile reaction to the disease. And in this experiment, performed by Nicolle, Blanc, and Conseil, ${ }^{92}$ the entire abdominal contents of the thirty-seven lice were injected intraperitoneally into a monkey.

In view of the paucity of the bacilli in the blood of infected individuals, we are forced to the conclusion that in all the experiments repeated feedings of a very large number of lice were necessary before sufficient blood had passed through them for at least a few to become infected.

Another observation which has been especially puzzling to all investigators ${ }^{16,}{ }^{22}, 49,181$ has been the fact that the lice seem only to become infective five to six or even ten days after the first feeding. Nicolle ${ }^{98}$ believed that this was evidence that the micro-organism was a protozoon, and that this length of time was needed for it to pass through some developmental cycle in the body of the louse, preliminary to becoming infective. Since the micro-organism is a bacillus, the only possible explanation is the one suggested originally by Ricketts and Wilder, ${ }^{131}$ that during this period the bacilli in the lice are undergoing an increase in numbers or in virulence.

There can be no doubt that the virulence is at least maintained in the body of the louse. An increase in the virulence of the bacilli during their residence in the louse is not improbable, but there is as yet no positive proof that it occurs. On the other hand, because of the relative infrequency of the organisms in the blood of infected individuals, even large numbers of lice can obtain only very few bacilii during the few feedings that they are given in the experiments. Undoubtedly, some days must therefore transpire before the bacilli in the infected lice have increased sufficiently in numbers to become potent. Our observations, therefore, supply an explanation for some of the previously inexplicable features of the louse experiments. It must be remembered however that under normal conditions the lice which ordinarily swarm over an infected individual have the opportunity to feed much more frequently and for a much longer time. 
The amount of blood which therefore passes through each individual louse during the entire course of a disease is much greater than in the experiments. Consequently, by the time the disease has run its course, very few lice, or even a single louse, probably is often capable of transmitting the infection.

From our observations we are able to throw some light upon another important phase of louse transmission. Nicolle, Conor, and Conseil, ${ }^{94}$ Ricketts and Wilder, ${ }^{118}$ and Anderson and Goldberger ${ }^{16}$ have noted that monkeys which have been exposed to the bites of infected lice may subsequently develop an immunity without having had fever or any other sign of illness. The two observations to be described, which we have recently been able to make on two individuals after exposure to the infection of typhus fever, demonstrate that the same thing may occur in human beings.

Dr. B.-During the course of this work it had been customary for one of us (Dr. B.) to bleed animals for the purposes of study, virus transmission, etc. No special precautions were taken to avoid infection, the blood of the infected animals often remaining on his hands throughout a series of experiments lasting over an hour. About five months ago, Dr. B. experienced some slight malaise and general muscular pains for several days, but they were not marked enough to require any attention.

Three or four weeks later his blood was studied serologically, preliminary to the proposed administration of vaccine. Much to our surprise, his serum gave $a++++$ complement fixation with typhus antigen and agglutinated a stock of typhus agglutinogen in a dilution of 1:500 (see serologic studies). As we had only observed serologic reactions of this degree in individuals who were convalescing from typhus fever, we had reason for believing that Dr. B. had recently passed through an infection, altho he had shown only exceedingly slight clinical manifestations of illness. This was confirmed by the fact that, as in convalescents from typhus fever, the serologic phenomena gradually diminished in intensity after the first month, so that by the end of four months both complement fixation and agglutination became practically negative.

Whether the infection occurred with or without the intermediary agency of the louse could not be ascertained. Dr. B. came into contact with most of the patients with endemic typhus fever, but usually only after their clothing had been removed and they had been bathed.

Miss L.-With the observation on Dr. B. in mind, studies were also made on two nurses, Miss L. and Miss $H$., who had recently returned from Serbia after nursing for almost three months at Valjevo. The patients under their care had been covered with vermin. Miss L. asserted that she had been repeatedly bitten by lice and that on at least two occasions she had removed lice from her clothes. The serologic studies on Miss $H$. were negative. The serum of Miss $L$. gave a ++++ fixation with typhus antigen and firmly agglutinated typhus bacilli in a dilution of $1: 200$. 
These observations permit of only one interpretation. Both Dr. B. and Miss L. were exposed to infection and shortly thereafter their blood was found to contain specific antibodies in amounts only observed in individuals who have recently recovered from the disease. It is therefore reasonable to assume that at the time of their exposure they had been infected with the bacilli, but in quantities insufficient to induce the clinical manifestations of the disease. In view of the absolute immunity of monkeys after exposure to a similar infection, ${ }^{16},{ }^{94},{ }^{115}$ the high titer of the specific bacterial antibodies in the blood of Dr. B. and Miss L. can be considered as evidence of at least a partial, if not an absolute, immunity.

As we have met with two such instances in our small experience, they are probably not very uncommon.* In epidemics, such individuals who have become immune without actually having had the disease may subsequently act as carriers of the infected lice.

\section{CONCLUSIONS}

In the experiments cited in the preceding pages it has been shown that a bacillus, identical with that recovered from patients with typhus fever, can also be isolated from the blood of animals in which the disease has been reproduced by inoculation of typhus blood. In such animals, the frequency of the bacilli in the blood is directly proportionate to the severity of the illness. In individual animals it is greatest at the height of the disease.

It has also been shown that with the bacilli isolated from epidemic cases of typhus fever, it is possible to reproduce the disease in animals. And furthermore, at the height of the disease in such animals, the identical organism can be recovered from the circulating blood.

Finally, it has been shown that typhus blood is only infective if it contains a sufficient number of these bacilli.

- Since this was written, we have had the opportunity of studying eight other contacts, individuals who were exposed to the infection of typlus fever but did not develop the disease. The serum of three of the contacts gave a ++ to +++ fixation with typhus antigen and agglutinated the bacilli in dilutions from 1:200 to 1:500. Therefore, specific agglutinins and complement-fixing bodies have been demonstrable in the blood of five out of the ten contacts studied. This is very significant in view of the fact that in the sera of over one hundred non-contact controls, complement fixation was never observed and specific agglutinins were never found in dilutions above 1:50. The studies on typhus contacts will be continued and will be reported later. It is already apparent however that individuals who are exposed to typhus fever may react with tbe production of specific antibodies without having had any clinical evidences of the disease.

Aside from its importance for the problem of the epidemiology of the disease, this fact mav be of significance as regards vaccine therapy. Should non-sensitized or sensitized vaccines prepared frcm epidemic and endemic strains of the typhus bacillus prove unsatisfactory, this olservation suggests the advisability of testing, with all proper precautions, the value of the inoculation of small numbers of living bacilli beginning with those obtained from endemic cases. 
From these observations and the results of the bacteriologic and serologic studies, we believe ourselves justified in concluding that this bacterium is the causative agent in typhus exanthematicus.

\section{BIBLIOGRAPHY}

1. Anderson: Jour. Am. Med. Assn., 1913, 60, p. 1845.

2. Anderson: Jour. Med. Research, 1914, 30, p. 467.

3. Anderson and Goldberger: U. S. Pub. Health Rep., 1909, 24, p. 1861.

4. Anderson and Goldberger: Ibid., 24, p. 1941.

5. Anderson and Goldberger: Ibid., 1910, 25, p. 177.

6. Anderson and Goldberger: Ibid., 1912, 27, p. 149.

7. Anderson and Goldberger: Ibid., 1912, 27, p. 835.

8. Anderson and Goldberger: Proc. Soc. Exper. Biol. and Med., 1909-10, 7, p. 85 .

9. Anderson and Goldberger: Ibid., 1911-12, 9, p. 66.

10. Anderson and Goldberger: Jour. Med. Research, 1910, 22, p. 469.

11. Anderson and Goldberger: Jour. Am. Med. Assn., 1910, 59, p. 514.

12. Anderson and Goldberger: New York Med. Jour., 1912, 95, p. 976.

13. Anderson and Goldberger: Jour. Infect. Dis., 1912, 11, p. 402.

14. Anderson and Goldberger: Jour. Am. Med. Assn., 1913, 60, p. 1845.

15. Anderson and Goldberger: Tr. Fifteenth Internat. Cong. Hyg. and Dermog., 1913, 2, p. 17.

16. Anderson and Goldberger: Collected Studies on Typhus, Pub. Health Bull. 86, Hyg. Lab., Washington, D. C., 1912.

17. Arzt and Gerl: Arch. f. Dermat. u. Syph., Orig., 1913, 118, p. 386.

18. Balfour and Porter: Edinburgh Med. Jour., 1889, 6, p. 522.

19. Barûkin: Russk. Vrach., 1909, 8, p. 46.

20. Benjasch: Russk. Vrach., 1899, 20, p. 1287. Abstr. in Baumgarten's Jahresbr., 1899, 15, p. 134.

21. Bernstein and Epstein: Jour. Infect. Dis., 1906, 3, p. 772.

22. Bory: Amtsarzt, 1912, 4, p. 413.

23. Botkin and Simnitzki: Ztschr. f. klin. Med., 1911, 72, p. 271.

24. Brill: New York Med. Jour., 1898, 67, pp. 48, 77.

25. Brill: Am. Jour. Med. Sc., 1910, 139, p. 484.

26. Brill: Ibid., 1911, 162, p. 196.

27. Brill: Med. Rec., New York, 1911, 79, p. 633.

28. Brill: Ibid., 1912, 81, p. 324.

29. Brill: Ibid., p. 1037.

30. Bri1l: Jour. Am. Med. Assn., 1911, 57, p. 1854.

31. Brill: Brit. Med. Jour., 1913, 2, p. 388.

32. Calmette: Ann. de Microorg., 1893 (v. Gouget).

33. Cathoire: Compt. rend. Soc. de biol., 1910, 619, p. 117.

34. Chantemesse: Bull. et mém. Soc. méd. d. hôp. de Paris, 1893, 10, p. 618.

35. Charles: Jour. Indiana Med. Assn., 1912, 5, p. 481.

36. Cheesman (v. McCampbell).

37. Cheinisse: Semaine méd., 1912, 32, p. 145.

38. Conseil: Le typhus exanthématique en Tunisie: épidémie de 1906, Paris, 1907.

39. Crawford: Proc. Roy. Soc. Med., 1912-13, 6, Sec. Hist. Med., p. 6.

40. Curtis and Combemale: Compt. rend. Soc. de biol., 1893, 5, p. 441.

41. Dreyer: Arch. f. Schiffs u. Trop. Hyg., 1911, 15, p. 319. 
42. Dubief and Brühl: Arch. de méd. expér. et d'anat. path., 1894, 6, p. 224.

43. Escalona: Am. Jour. Pub. Hyg., 1910, N. S., 6, p. 553.

44. Fried and Sophian: Am. Jour. Med. Sc., 1911, 162, p. 88.

45. Friedman: Arch. Int. Med., 1911, 8, p. 427.

46. Fuchs: Allg. med. Centr.-Ztg., 1896, 54, p. 647.

47. Fuerth: Ztschr. f. Hyg. u. Infectionskrankh., 1911-12, 70, p. 333.

48. Fuerth: Arch. f. Schiffs u. Tropen Hyg., 1912, 16, p. 241.

49. Fuerth: Centralbl. f. Bakteriol., I, O., 1914, 51, p. 79.

50. Galesesco and Slatineano: Compt. rend. Soc. de biol., 1906, 61, p. 14.

51. Gaviño and Girard: Pub. del Inst. Bacteriol. Nacionale de Méxicò, 1910 and 1911.

52. Goldberger and Anderson: U. S. Pub. Health Rep., 1912, 27, p. 297.

53. Gotschlich: Deutsch. med. Wchnschr., 1903, 29, p. 329.

54. Gouget: Semaine méd., 1893, 13, p. 193.

55. Hegler and von Prowazek: Berl. klin. Wchnschr., 1913, 2, p. 2035.

56. Hlaval: Semaine méd., 1889, 9, p. 420.

57. Hlva: Centralb1. f. Bakteriol., I, O., 1850,7, p. 66.

58. Hlava: Ibid., 1902, 32, p. 263.

59. Horiuchi: Centralbl. f. Bakteriol., I, O., 1908, 66, p. 586.

60. Jablons: Jour. Med. Research, 1914, 25, p. 131.

61. Kelsch: Semaine méd., 1893, 13, p. 189.

62. Kireeff: Centralbl. f. Bakteriol., I, O., 1905, 38, p. 518.

63. Klebs: Internat. Med. Cong., 1881, 1, p. 323.

64. Klodnitsky: Russk. Vrach, 1S07, 6, p. 1004 ; Centralbl. f. Bakteriol., I, O., 1912,67, p. 338.

65. Krompecher, Goldziehr and Augyan: Centralbl. f. Bakteriol., I, O., 1909, 59 , p. 612.

66. Lee: Boston Med. and Surg. Jour., 1913, 168, p. 122.

67. Legrain: Gaz. d. hôp., Paris, 1895, 68, p. 766; Gac. méd., México, 1913, 8 , p. 410 .

68. Lévy: Gaz. d. hôp. Paris, 1913, 85, p. 2097.

69. Lewaschew: Deutsch. med. Wchnschr., 1892, 18, p. 279.

70. Lewin: Centralbl. f. Bakteriol., I, O., 1911, 60, p. 498.

71. Lewis: Tr. Assn. Am. Phys., 1911, 26, p. 234.

72. Liborius: Quoted by Besson, Technique microbiologique et sérothérapique, Paris, 1914, p. 105.

73. Libman: Jour. Med. Research, 1901, 1, p. 84.

74. Libman: Johns Hopkins Bull., 1906, 17, p. 215.

75. Ljublinski: Quoted by Blumenthal and Sipkerdow, Centralbl. f. Bakteriol., I, O., 1905, 38, p. 359.

76. Louria: Med. Rec., New York, 1911, 80, p. 424.

77. Love: Jour. Path. and Bacteriol., 1905, 10, p. 296.

78. Markl: Wien. klin. Wchnschr., 1913, 26, p. 1234.

79. McCampbell: Jour. Med. Research, 1910, 23, p. 71.

80. McWeeney: Brit. Med. Jour., 1898, 1, p. 881.

81. Moczutkowski: St. Petersb. med. Wchnschr., 1900, 25, p. 30 . Allg. med. Centr.-Ztg., 1900, 69, p. 1055.

82. Mott: Brit. Med. Jour., 1883, 2, p. 1058.

83. Moreau and Cochez: Gaz. hebd. de méd., 1888, 25, p. 388.

84. Mueller: Arch. f. Hyg., 1913, 81, p. 307.

85. Mueller: München. med. Wchnschr., 1913. 60, p. 1364.

86. Newell and Allan: South. Med. Jour., 1914, 7, p. 564. 
87. Nicoll, Krumwiede, Pratt, and Bullowa: Jour. Am. Med. Assn., 1912, 59 , p. 521 .

88. Nicolle: Compt. rend. Acad. d. sc., 1909, 149, p. 157.

89. Nicolle: Jour. Hyg., Cambridge, 1910, 10, p. 135.

90. Nicolle: Ann. d. l'Inșt. Pasteur, 1910, 24, p. 243.

91. Nicolle: Ibid., 25, pp. 1, 97.

92. Nicolle, Blanc and Conseil: Arch. de l'Inst. Pasteur de Tunis, 1914, 9, p. 84 .

93. Nicolle and Comte: Bull. Soc. Path. exot., 1910, 3, p. 214.

94. Nicolle, Compte and Conseil: Compt. rend. Acad. d. sc., 1909, 149, p. 149. 95. Nicolle, Compte and Conseil: Ibid., p. 486.

96. Nicolle, Conor and Conseil: Compt. rend. Acad. d. sc., 1910, 151, p. 685.

97. Nicolle, Conor and Conseil: Ann. de l'Inst. Pasteur, 1912, 26, pp. 250, '332.

98. Nicolle, Conor, Conseil and Jaeggy: Ann. de 1'Inst. Pasteur, 1911, 25, pp. $1,97$.

99. Nicolle and Conseil: Compt. rend. Acad. d. sc., 1910, 150, p. 1772; 151, p. 598.

100. Nicolle and Conseil: Ann. de l'Inst. Pasteur, 1912, 26, p. 321.

101. Noguchi: Jour. Exper. Med., 1912, 16, p. 199.

102. Otero: Memoria presentata a la Acad. de Mediciana de Mexico, $190 \%$.

103. Patek: Wisconsin Med. Jour., 1912, 11, p. 18.

104. Paullin: South. Med. Jour., 1913, 6, p. 36.

105. Plotz: Jour. Am. Med. Assn., 1914, 62, p. 1556; La Presse Méd., 1914, 43, p. 411.

106. Predjetschensky: Centralbl. f. Bakteriol., I, O., 1910, 55, p. 212.

107. Predjetschensky: Ibid., 1911, 58, p. 106.

108. Prieto: Cong. med. Mexico, 1910, 13, p. 309 (English text, p. 314.

109. Rabinowitsch: Centralbl. f. Bakteriol., I, O., 1909, 52, p. 173.

110. Rabinowitsch: Arch. f. Hyg., 1909, 71, p. 331.

111. Rabinowitsch: Russk. Vrach, 1912, 11, p. 1423. Abstr. in Deutsch. med. Wchnschr., 1912, 38, p. 2018.

112. Rabinowitsch: Arch. f. Hyg., 1913, 78, p. 186.

113. Rabinowitsch: Deutsch. med. Wchnschr., 1913, 39, p. 2199.

114. Rabinowitsch: München. med. Wchnschr., 1913, 60, p. 2451.

115. Rabinowitsch: Berl. klin. Wchnschr., 1914, 51, p. 1458.

- 116. Report of Committee of the New York Acad. of Med., 1910.

117. Ricketts and Wilder: Jour. Am. Med. Assn., 1910, 54, p. 463.

118. Ricketts and Willer: Ibicl., p. 1304.

119. Ricketts and Wilder: Ibid., p. 1373.

120. Ricketts and Wilder: Ibid., 55, p. 309.

121. Rizzuti and Scordo: Bull. Soc. path. exot., 1912, 5, p. 778.

122. Roussel: Pennsylvania Med. Jour., 1913-14, 17, p. 729.

123. Sergent, Foley and Vialatte: Compt. rend. Acad. d. sc., 1914, 118, p. 964.

124. Sokalski: Russk. Vrach, 1914, 13, p. 654.

125. Sol: Orvosi hetil., 1912, 56, p. 6.

126. Spillman: Rev. de méd., 1896, 14, p. 609. Abstr. in Baumgarten's Jahresb., 1896, 12, p. 569.

127. Strouse: Illinois Med. Jour., 1913, 23, p. 37.

128. Thoinot and Calmette: Ann. de 1'Inst. Pasteur, 1892, 6, p. 39. 
129. Veillon: Quoted by Besson, Technique microbiologique et sérothérapique, Paris, 1914, p. 105.

130. Weinschall: Abstr. in Baumgarten's Jahresb., 1892, 8, p. 296.

131. Wilder: Jour. Infect. Dis., 1911, 9, p. 9.

132. Wilder: Jour. Am. Med. Assn., 1914, 63, p. 939.

133. Wilson: Jour. Hyg., Cambridge, 1909, 9, p. 9.

134. Wilson: Ibid., 1910, 10, p. 155.

135. Yersin and Vassal: Philippine Jour. Sc., 1908, 3, p. 131.

136. Ziegel: Med. Rec., New York, 1910, 77, p. 1087.

\section{EXPLANATION OF PLATE 1}

Fig. 1.-Bacillus typhi-exanthematici: Gram's stain. $\times 1000$.

Fig. 2.-Colony of Bacillus typhi-exanthematici - with area of precipitation - in originai blood culture.

Fig. 3.-Tube showing growth (seven days) of Bacillus typhi-exanthematici on serum glucose agar. Note whitening of medium (precipitation).

Fig. 4.-A control tuhe of glucose serum agar. 


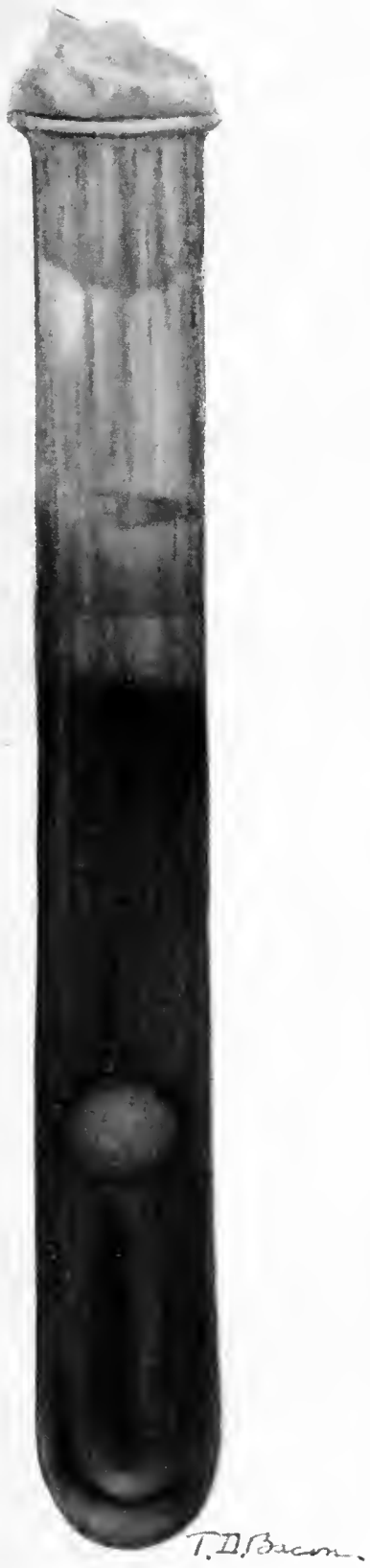

Figure 2

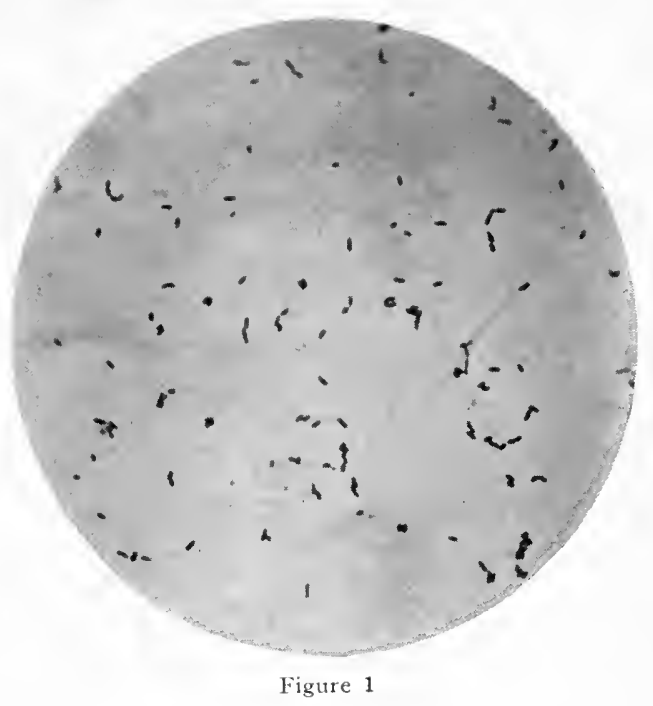

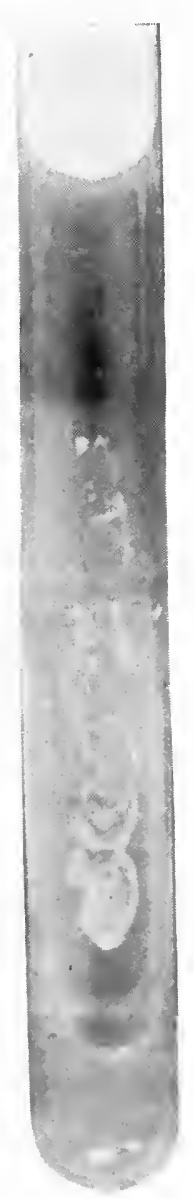

Figure 3

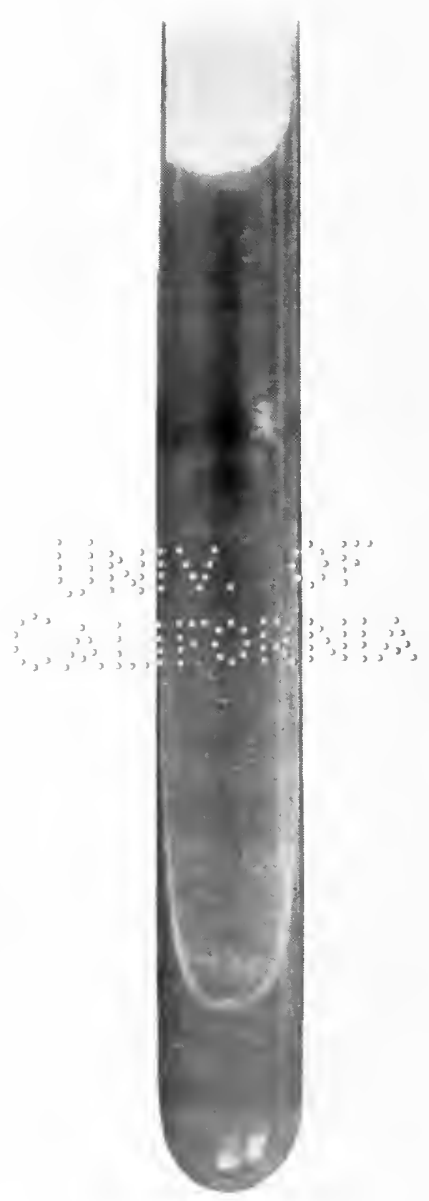

Figure 4 
$\because \because: \quad \because \because \vdots \vdots \vdots$

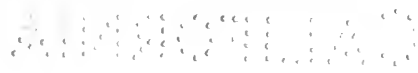




Tin'sing 